Received 15 March 2019; accepted 3 June 2019.

Available online 1 October 2019

\title{
معبد رابى سمحاه بحارة اليهود القرائين بالقاهرة ،دراسة تاريخية \\ Rab Simḥāh Synagogue \\ In the Kariates's Jewish quarter at Cairo; Historical study
}

\author{
د/ احمد زكريا \\ مدرس تاريخ العمارة والفنون، كلية الهندسة جامعة عين شمس \\ Ahmed_zakaria@eng.asu.edu.eg
}

الملخص

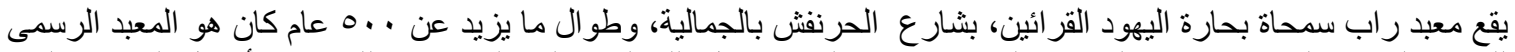

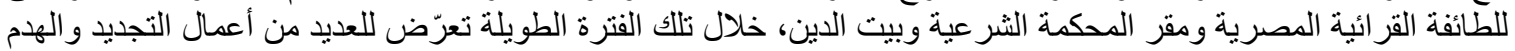

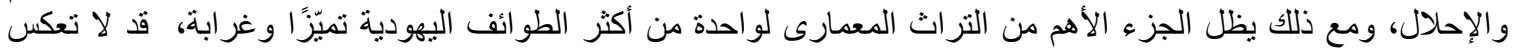

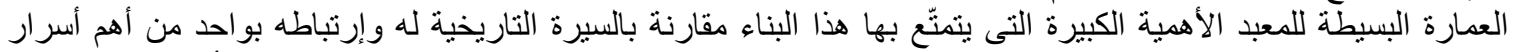

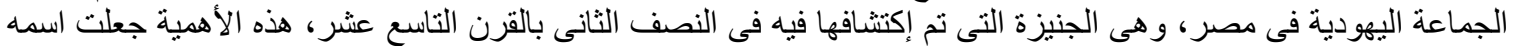

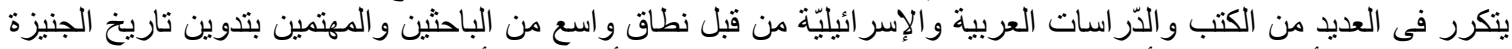

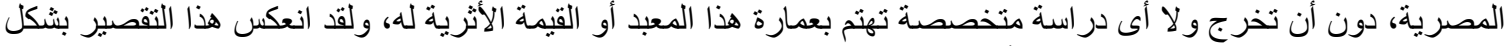
و اضح على حالة الإهمال و التهميش التى أصابته و التى تمهذ لهذمه وطمس كل المعالم التاريخيّة التى يرصدها.

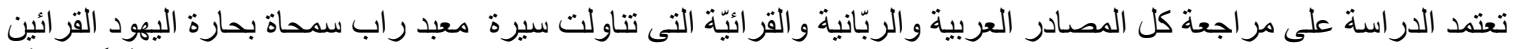

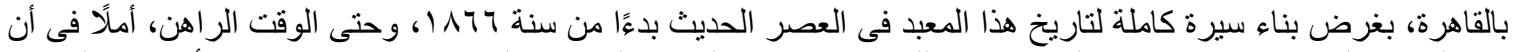

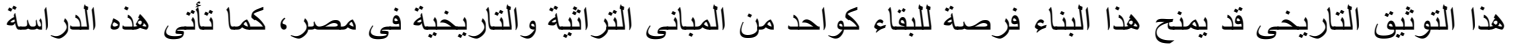

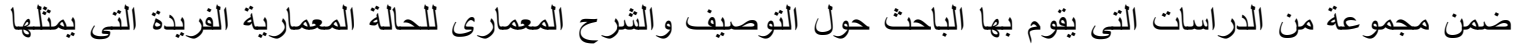

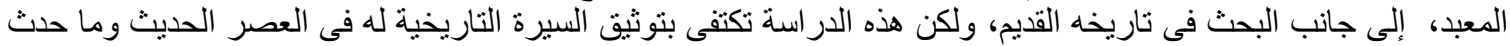
به من أعمال ترميم و نطوير ودر اسات ميدانية وتاريخية، وهو ما اسنطاعت الدراسة أن ترصده بمنتهى الدقة و الحيادية.

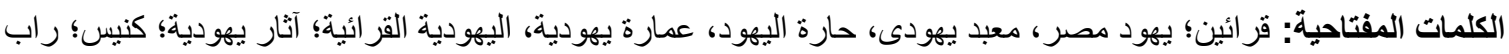

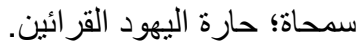

المقدّمة

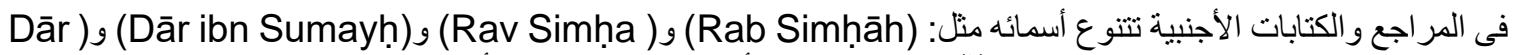

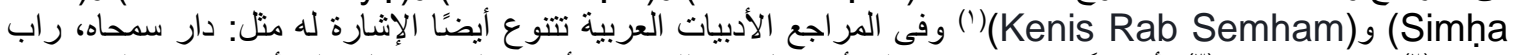

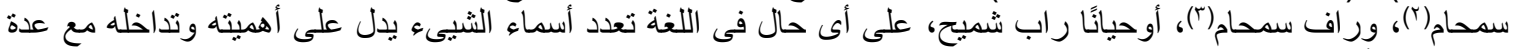

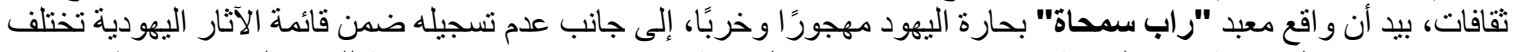

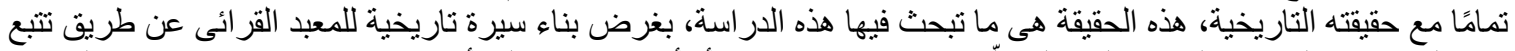

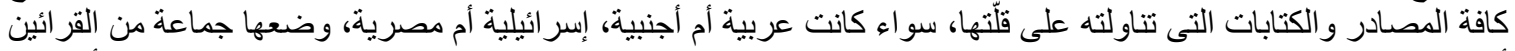

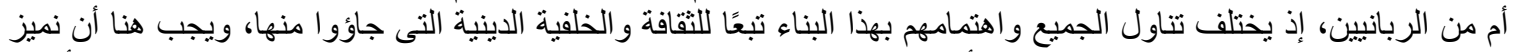

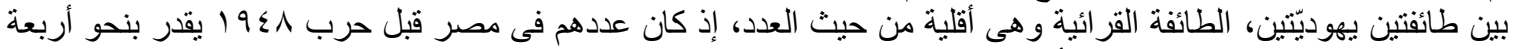

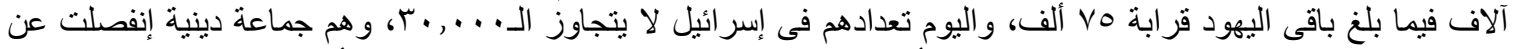

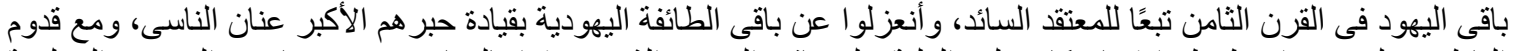

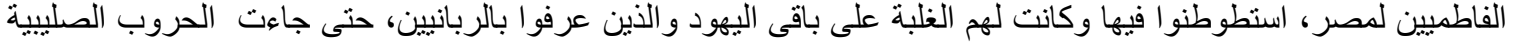

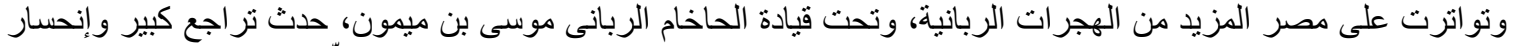

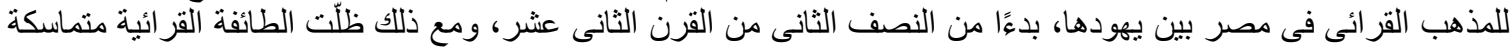

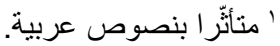

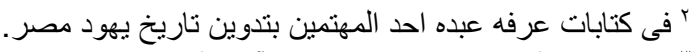

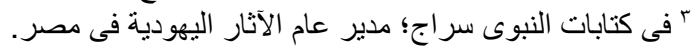




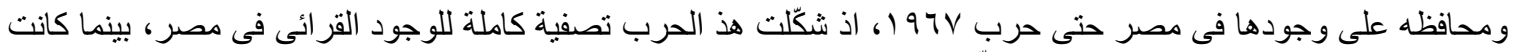
حروب 1919 1 ـ1907 هي الحروب التى شكّلت الهجرة الربانية عن مصر.

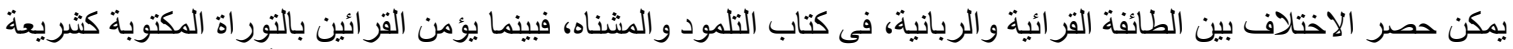

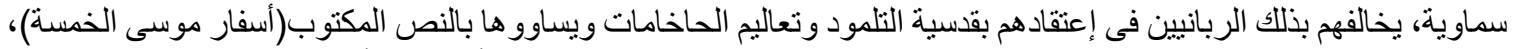

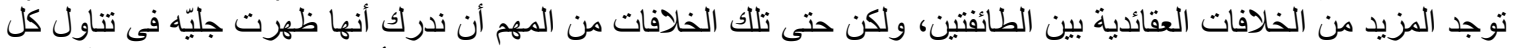

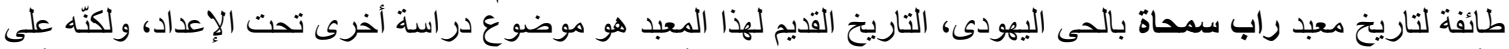

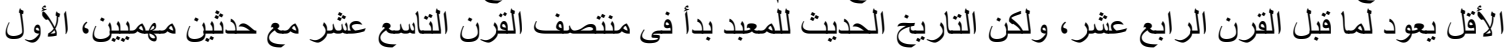

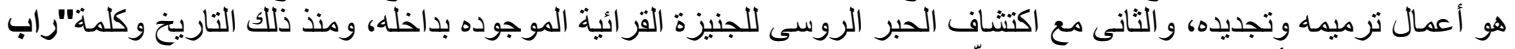

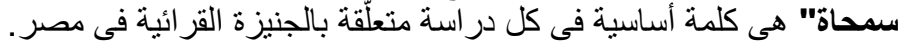

\section{ا الاراسات السابقة لمعبد رابى سمحاه بحارة اليهود}

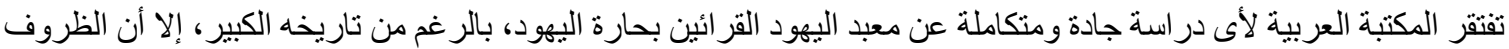

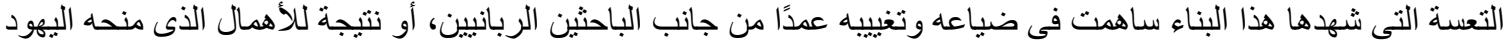

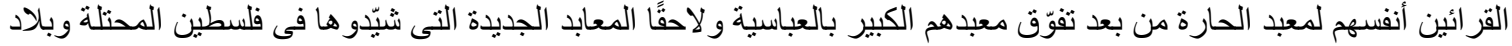

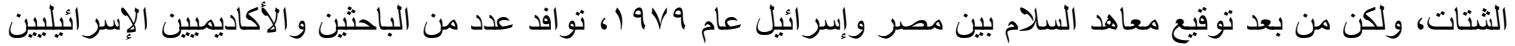

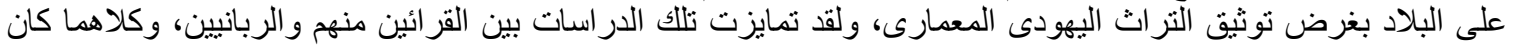

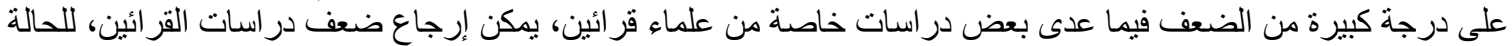

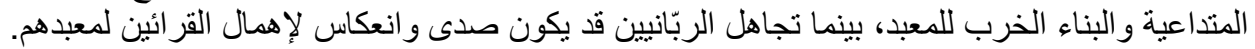

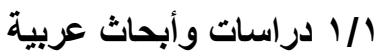

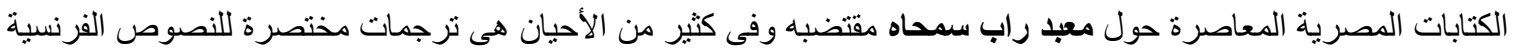

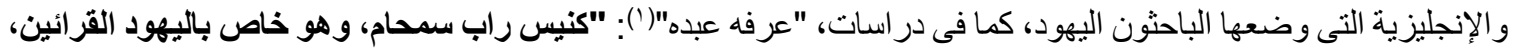

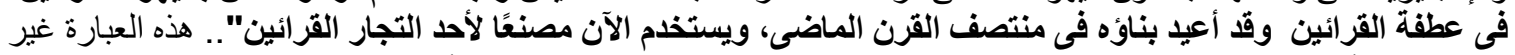

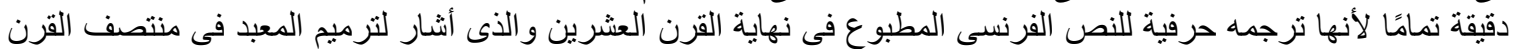

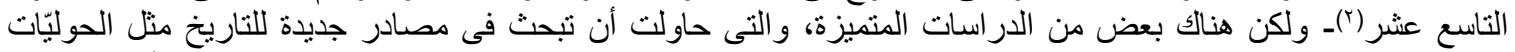

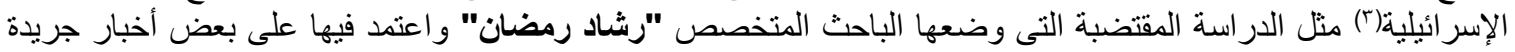

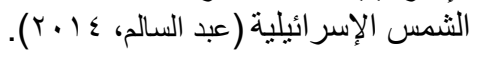

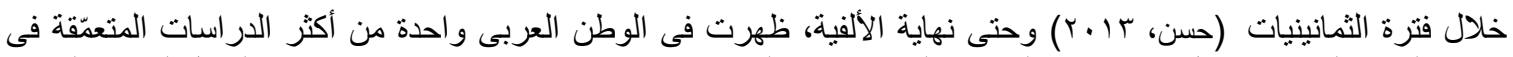

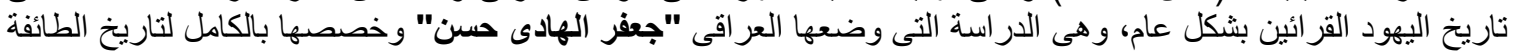

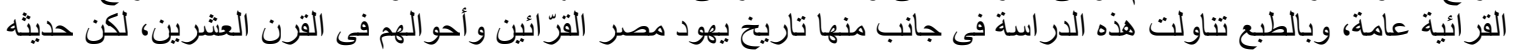

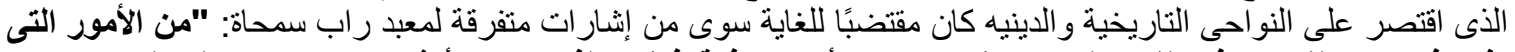

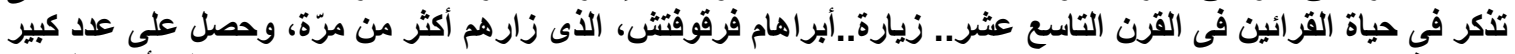

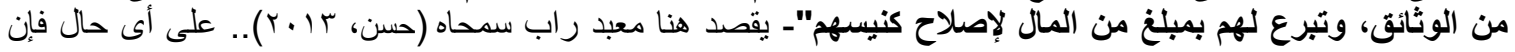

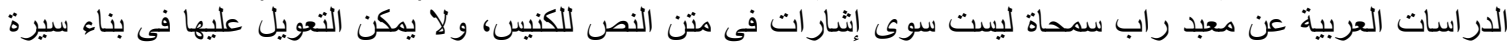
تاريخية لهذا البناء.

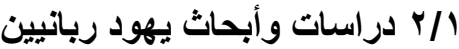

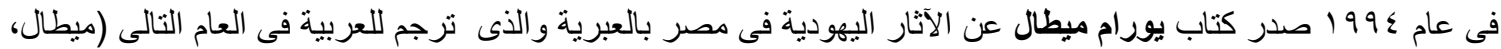

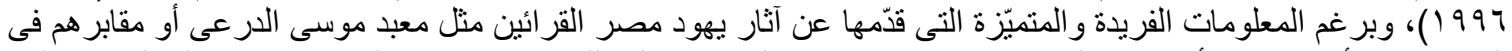

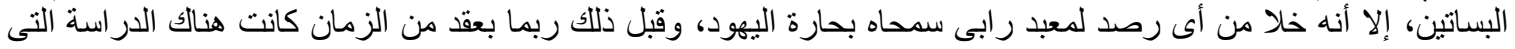

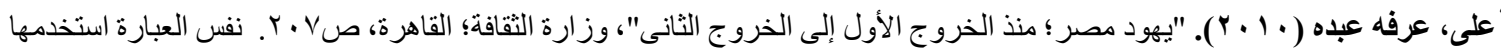

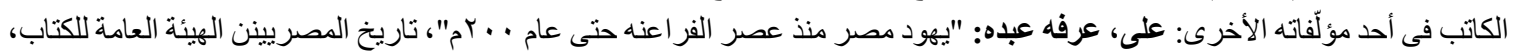

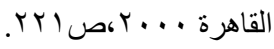

rإنظر الدراسات السابقة لأبحاث اليهود الربانيين (ASPCJE Committee: "Juifs d'Égypte:Images et textes",2nd ed.

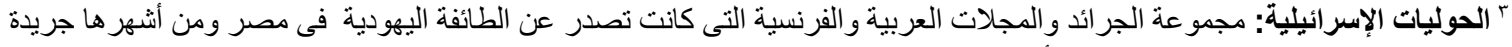

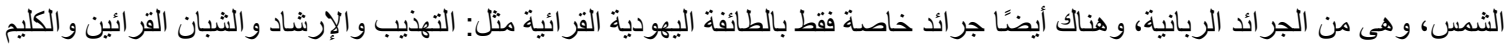
إلى جانب المنشورات المنفرقة التى كانت تصدر عن الحاخامخانة الإسر ائيلية القرائية. 


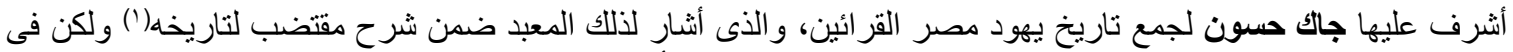

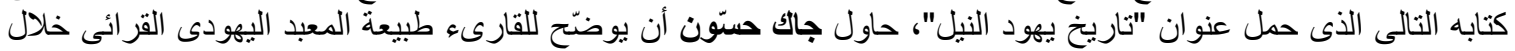

مقالة كبيرة خصصها عن اليهود القرائين(Committee, 1984) :

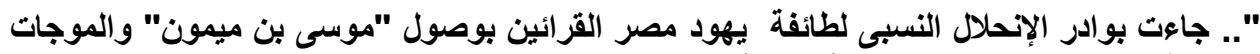

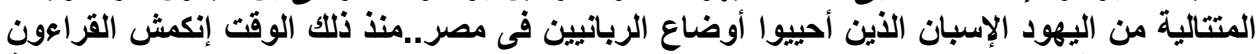

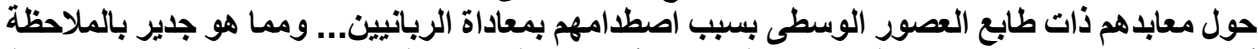

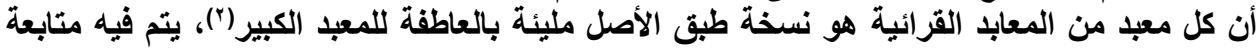

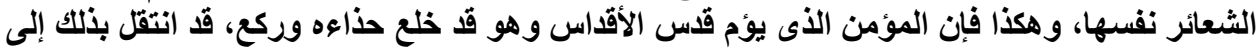

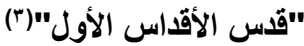

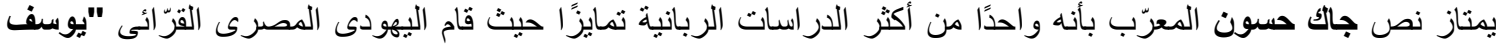

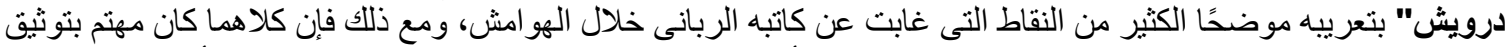

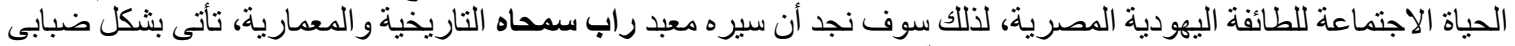

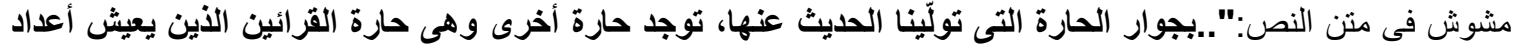

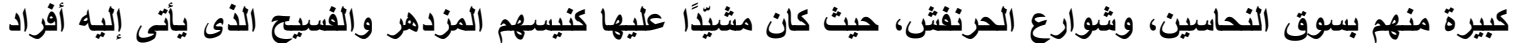

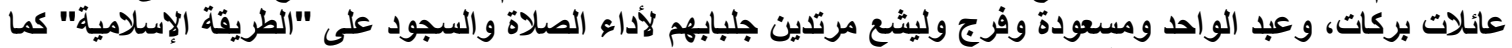

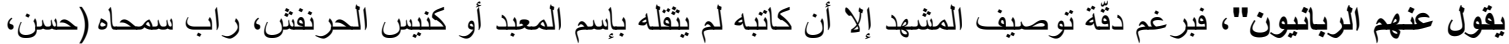

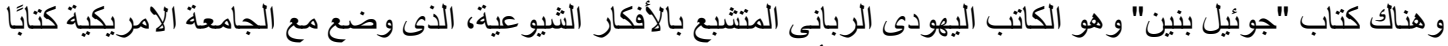

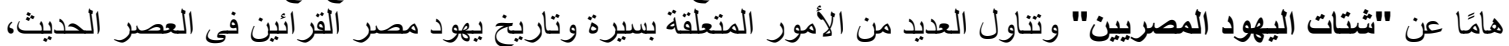

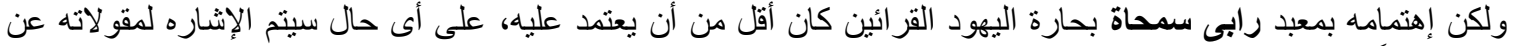

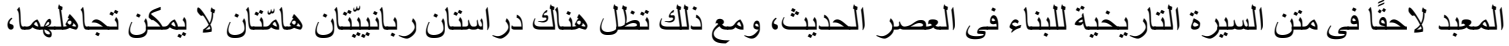

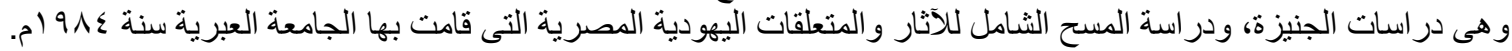

\section{ا / / / معبد راب سمحاة فى ضوء دراسات الجنيزة}

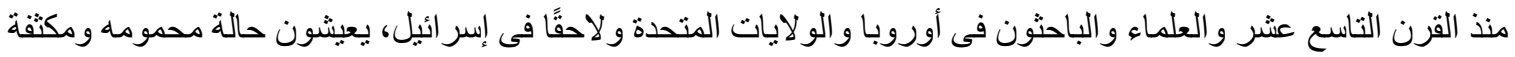

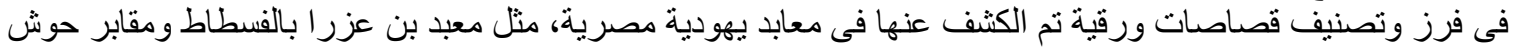

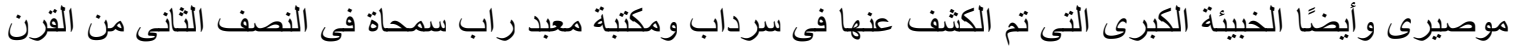

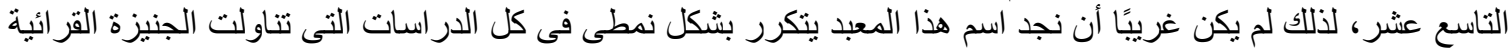

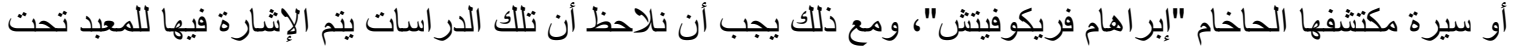

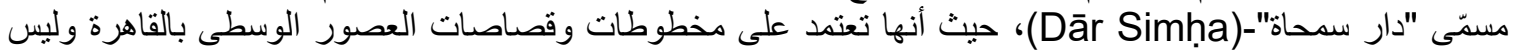
السيرة الحديثة ليهود مصر القرائين.

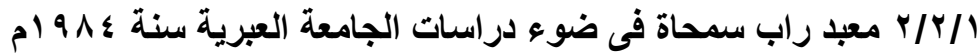

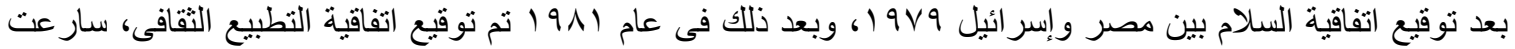

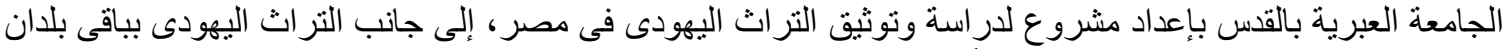

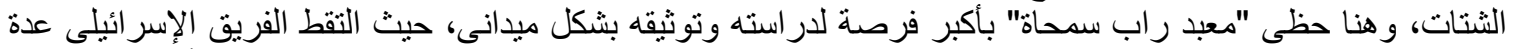
صور فوتوغر افية له بالإضافة لمسح عمر انى ساعدهم فى إعادة رسم المساقط الأفقية وو اجهات المعبد لاحتقاً فئ القدس.

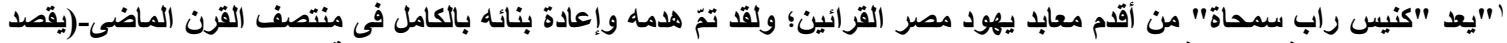

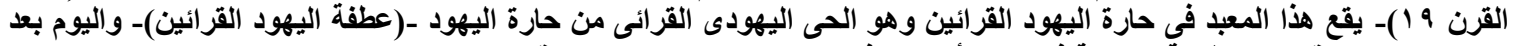
مرور . .9 عام قضنها الطائفة القرائية فى مصر أصبح هذا المعبد مستخدم كمصنع من قبل تاجر بلاستيك".

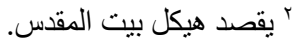

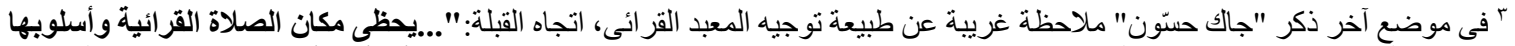

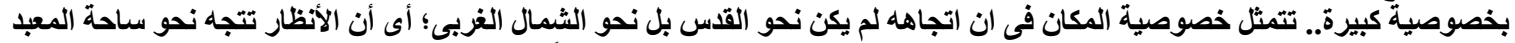

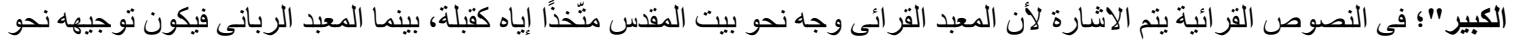

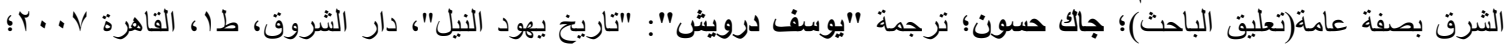


شكل (1) المسقط الأفقى لمعبد راب سمحاة وفقًا للدراسة التى وضعتها الجامعة العبرية له سنة عد 191

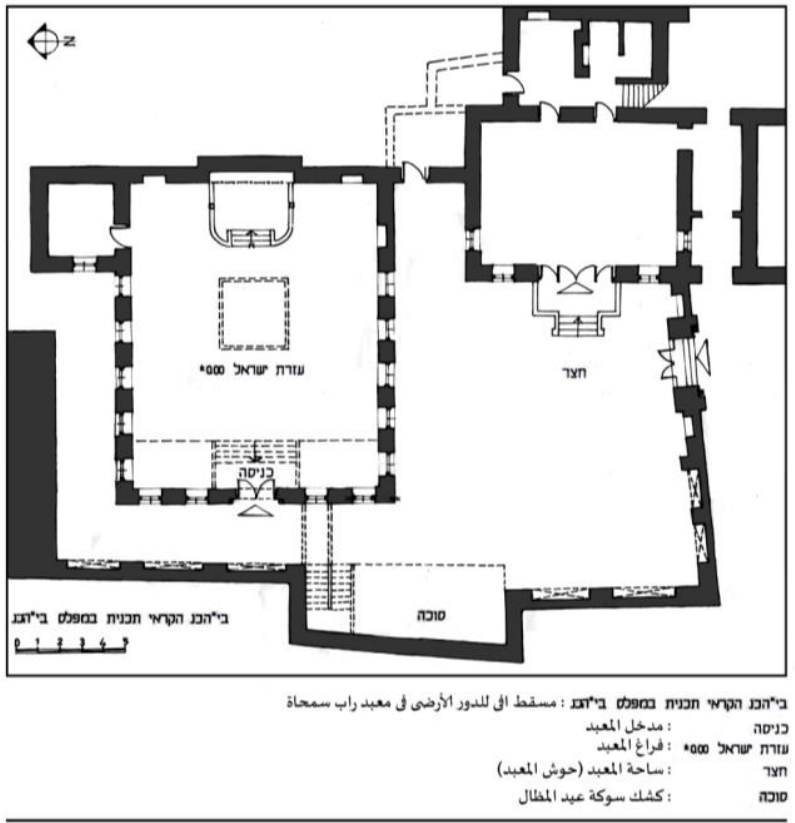

Re-drawing by the Author based on 1984 survey

$$
\text { آ/ دراسات وأبحاث يهود قرائين }
$$

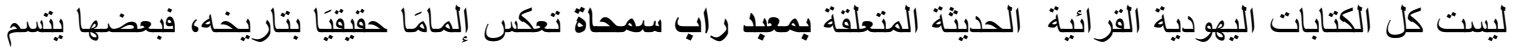

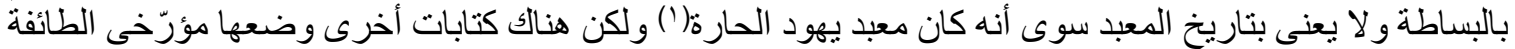

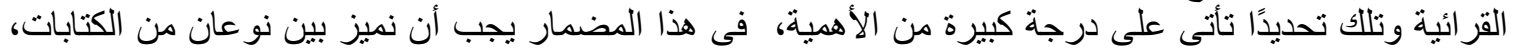

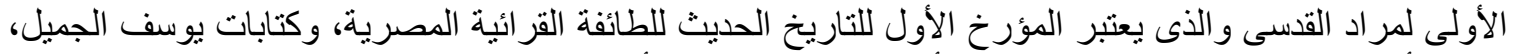

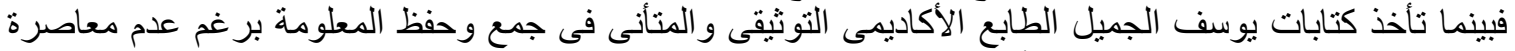

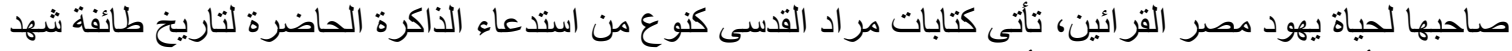

المرحلة الأخيرة من حياتها باعتباره أحد اعضاء المجلس المليات الملى لتلك الطائفة المنقرضة في مصر (KJA, 2016) .

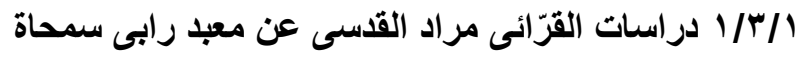

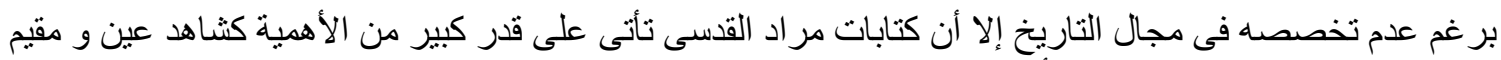

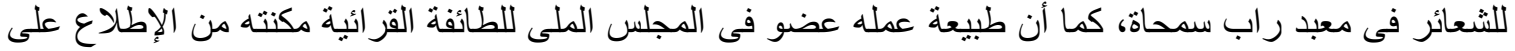

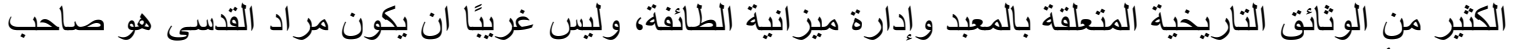

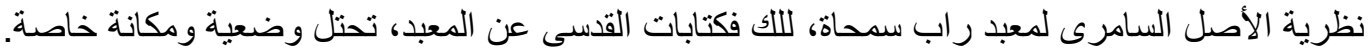

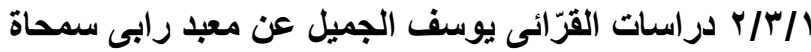

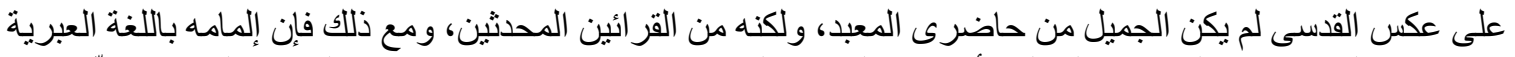

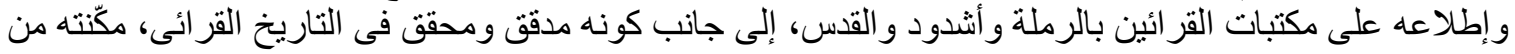

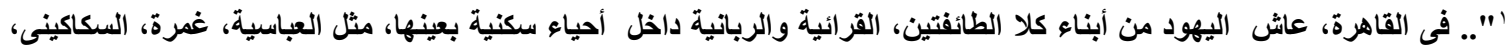

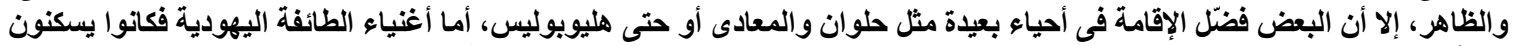

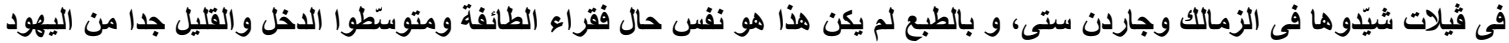

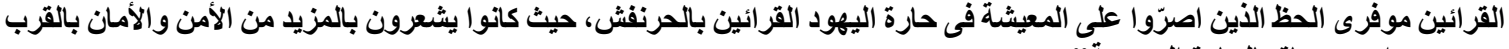


القيام بعمل جيد فى تحقيق التراث التاريخى ليهود مصر القر ائين، ولكنه يعتمد في كثير من مرجعياته على أبحاث قام

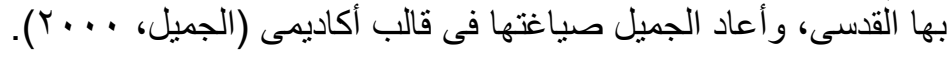

r ملاحظات هامة عند كتابة تاريخ معبد رابى سمحاة بحارة اليهود

عند كتابة السيرة التاريخية لمعبد راب سمحاة، يجب أن نميز مجموعة من الأمور المرتبطة بتاريخ المكان، فأمور

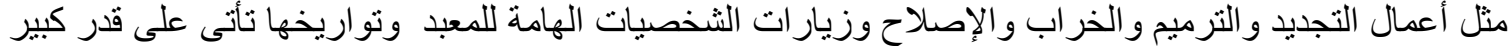

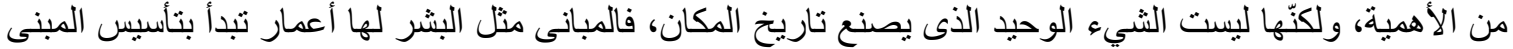

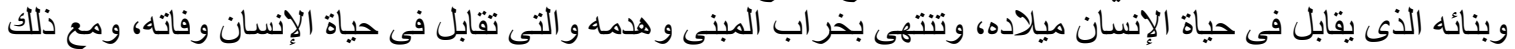

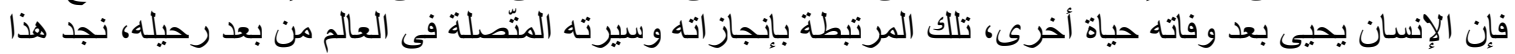

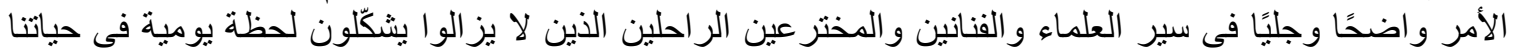

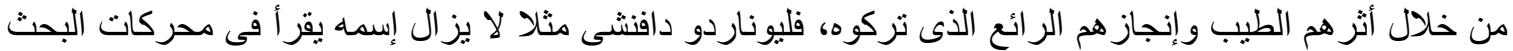

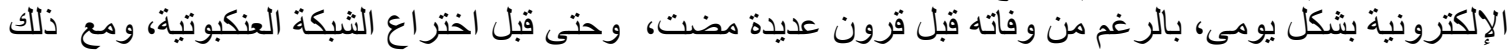

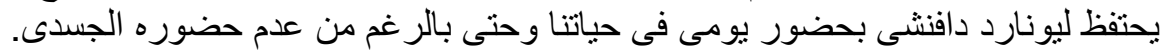

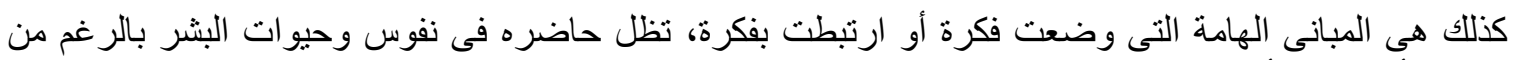

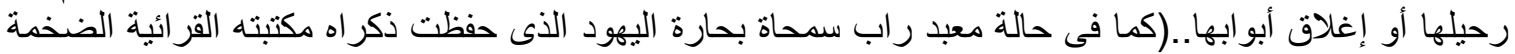

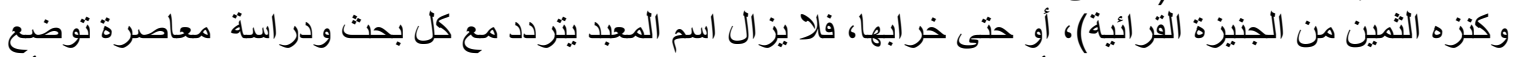

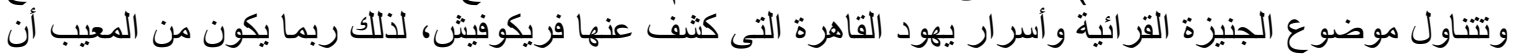

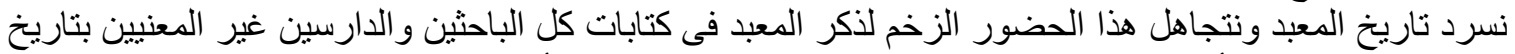

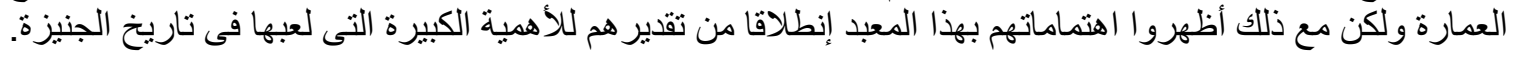

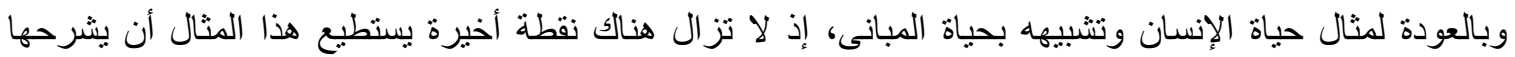

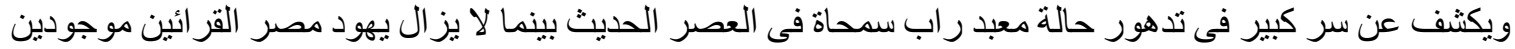

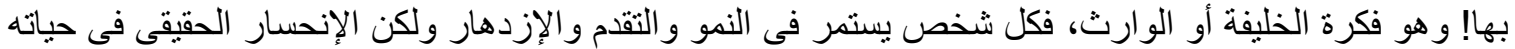

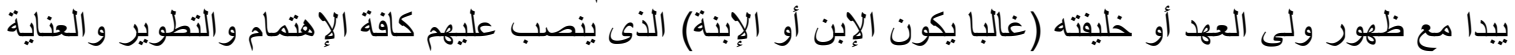

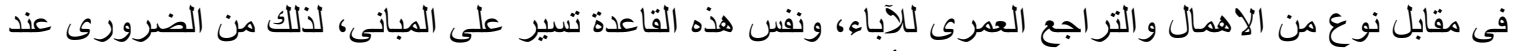

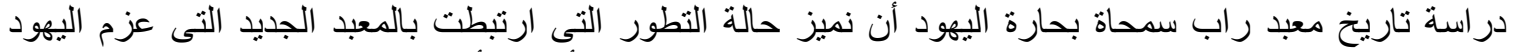

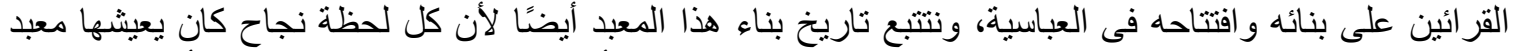

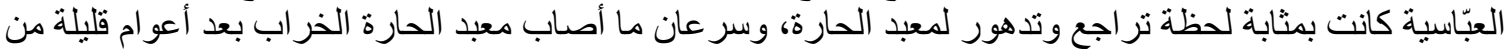

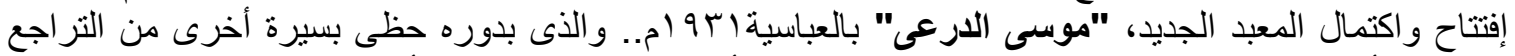

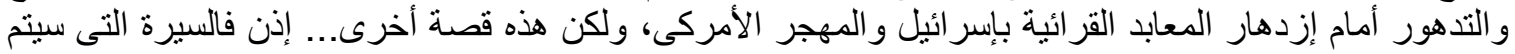

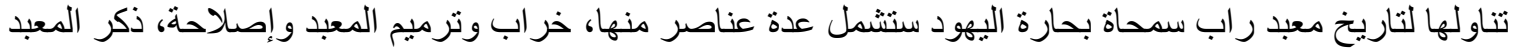

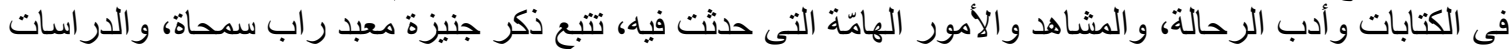
التاريخية التى جاءت على ذكره، إزدهار و وعمار معبد اليهود القر ائين بالعباسية.

\section{ب تاريخ معبد راب سمحاه بحارة اليهود القزائين فى العصر الحديث}

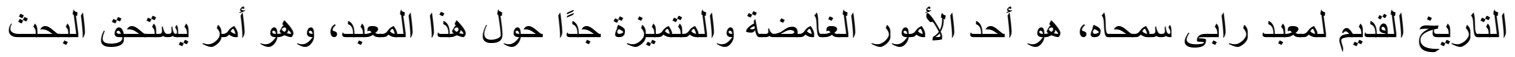

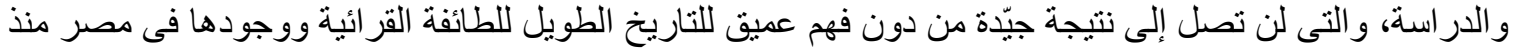
زمن الفاطميين، لذلك ستعنى هذه الدر اسة بالسيرة التاريخية للمعبد منذ زيارة الحبر الروسى إبر الهام فروكو فيتش له. 


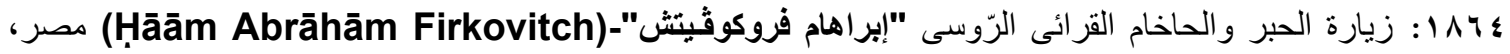

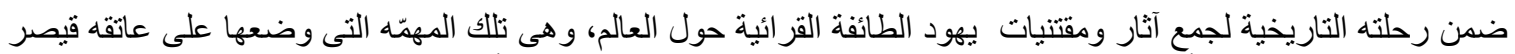

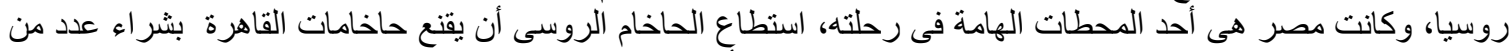

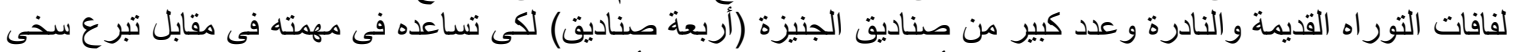

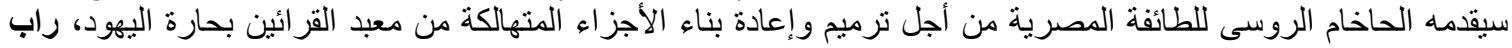

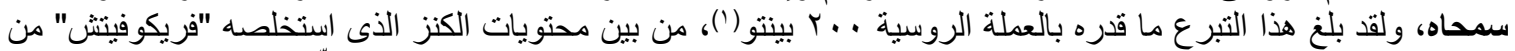

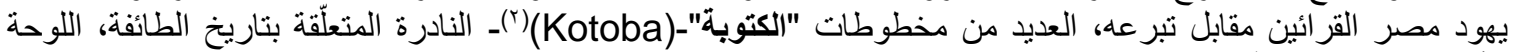

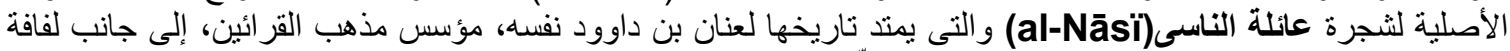

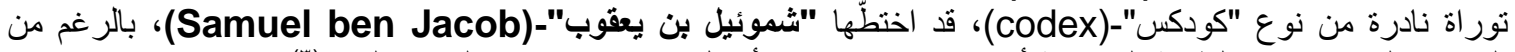
الخسارة الكبيرة إلا ان الطائفة المصرية أحسنت استثمار هذه الأمو ال •ووجهتها جميعًا لترميم المعبد (†).

شكل (ץ) صورة تعبيرية للحبر اليهودى القرائى، إبراهام فريكوفيتش، وهو يجلس فى مكتبه ببطرسبرج، يتفص المخطوطات اليهودية القرائية،

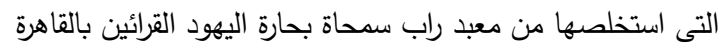

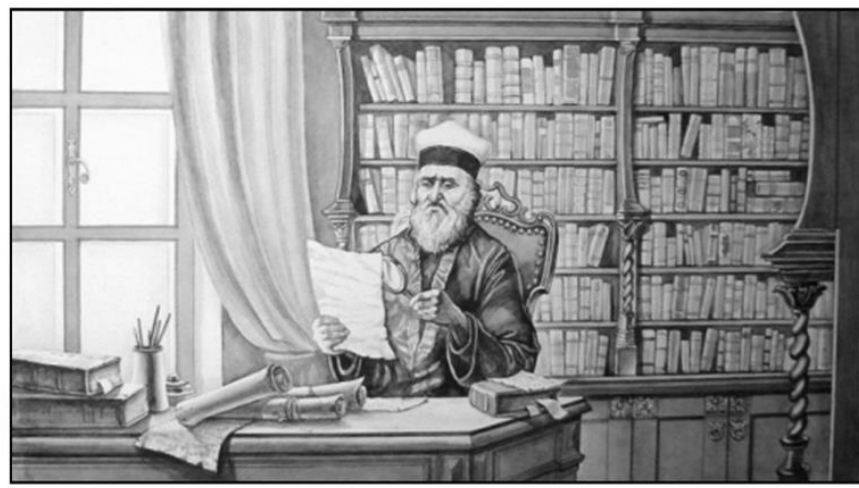

After: Dan Shapira: "Avraham Firkowicz in Istanbul", Karam Yayinlari Press 2003. Illustrated by S. P. Grecov

414 1 ا: إكتمال أعمال ترميم معبد رابى سمحاه و إفتتاحه لتُعائر الصلاوات، وبهذه المناسبة تم عمل لوحة رخامية تأسبسية

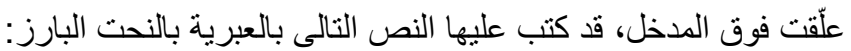

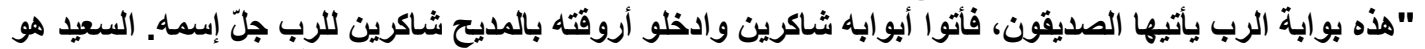

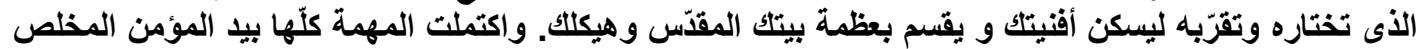

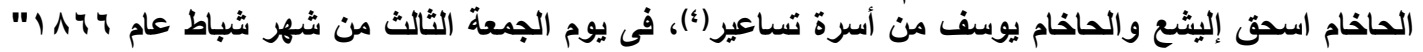

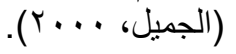

البينتو)(Pinto) الو احد يقدّر بـه V قرش (Piaster)صاغ.

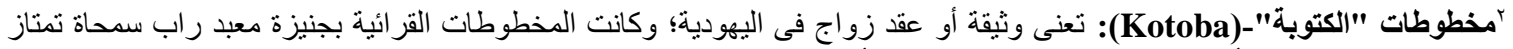

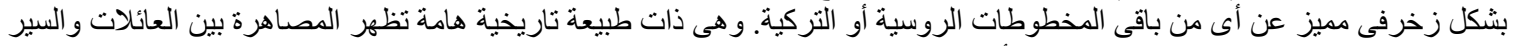

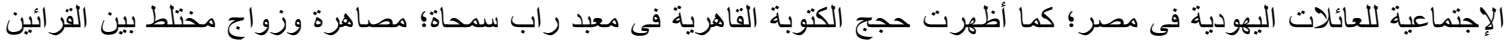
والربانيين.

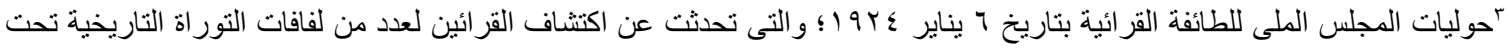

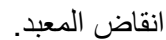
" تساعير: هذه هى الترجمة التى وضعها المترجمان "جمال أحمد الر افعى واحمد عبد اللطيف حماد" و الأدق أن تكون الكلمة "مسعودة" 


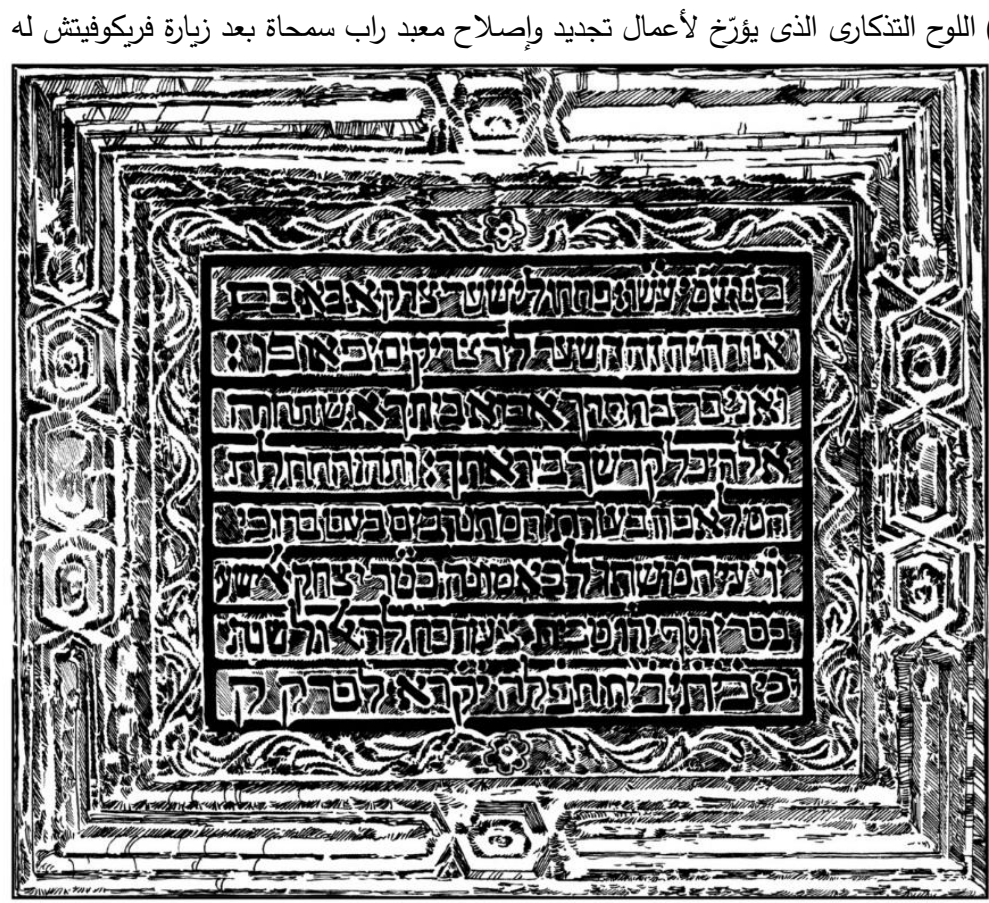

Rabi Simha Karaite Synagogue in 1984,

Engraved by the Author based on an old photograph by: Radovan, Zev

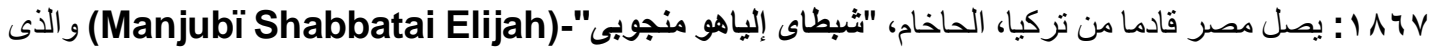

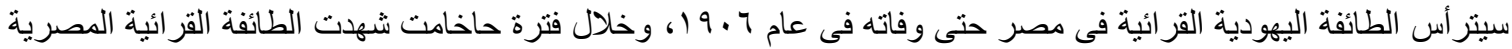

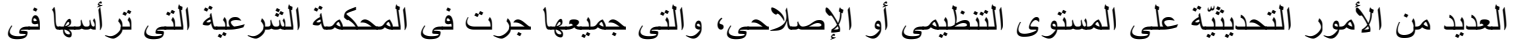

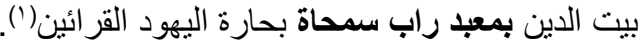

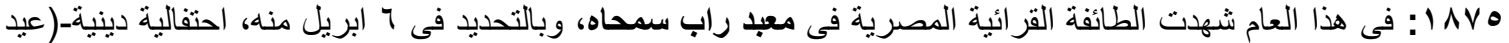

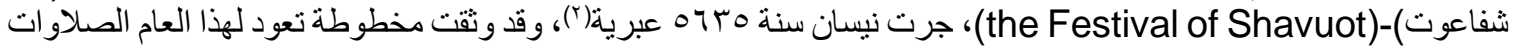

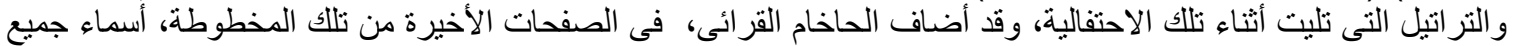

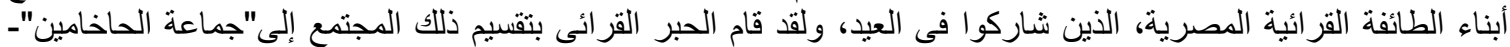

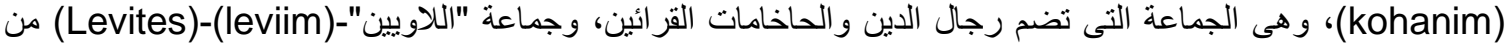

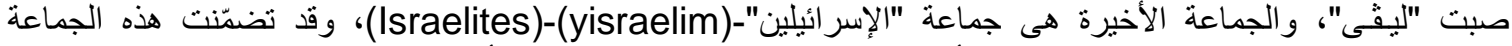

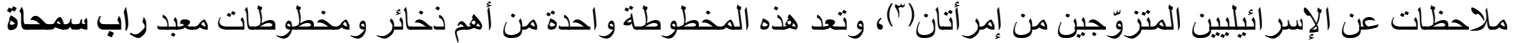

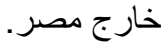

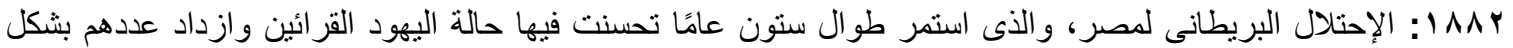

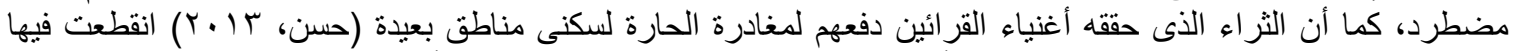

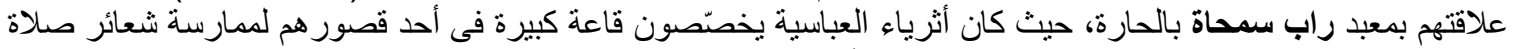

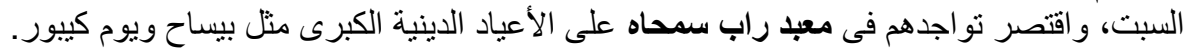

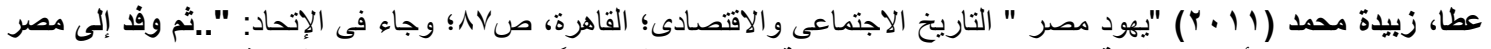

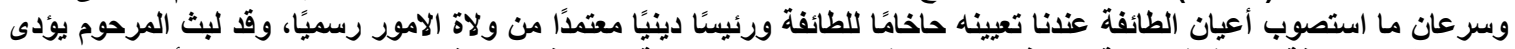

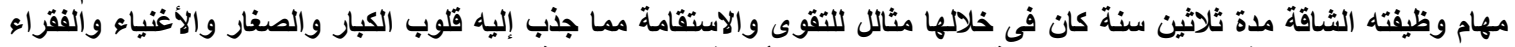

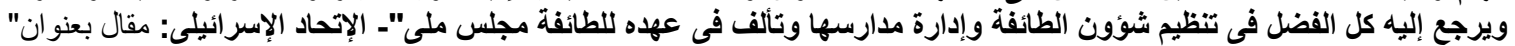
المرحوم الطيب الذكرى الحاخام شبطاى بن إلياهو منجوبى، حاخام باشى الطائفة سابقًا"، العدد رقم (0) من السنة الأولى؛ القاهرة، 10 يونية

${ }^{2}$ Dated Rosh Chodesh Nissan 5635 (April 6, 1875).

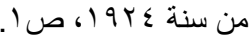

${ }^{3}$ Manuscript [ms kc22]: Machzor for the Festival of Shavuot (Egypt, 19th cent.): Machzor for the Festival of Shavuot, Hebrew, Egypt, 19th century, Ink on paper, leather binding, 99 leaves, Karaite Manuscript Collection KC22, The Magnes Collection of Jewish Art and Life, UC Berkeley 


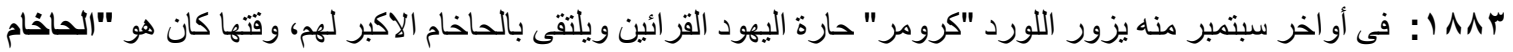

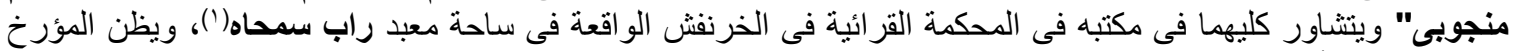

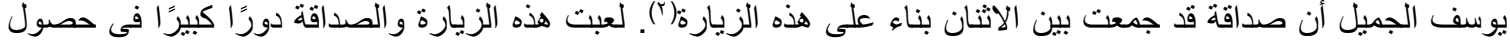

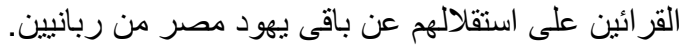

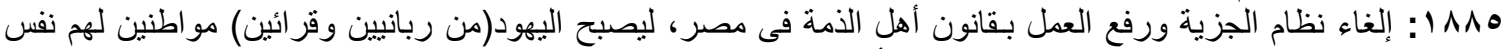

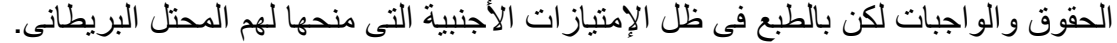

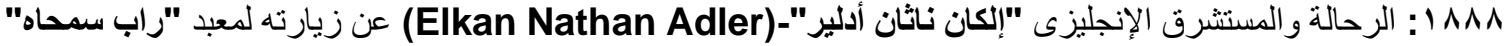

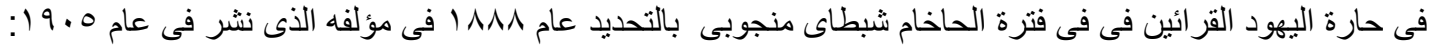

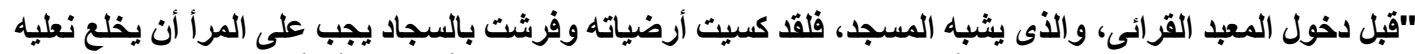
بالخارج. كان جموع المصلين يقفون أو يركعون فوف السجاجيد، لم يكن هناك أى مقعد أو أى هيكل) (Almemar) فى منتصف البناء."

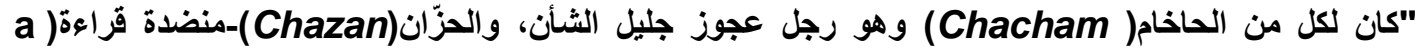

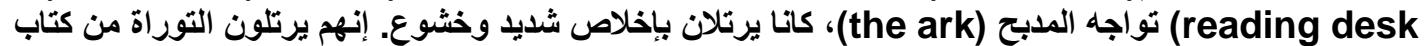

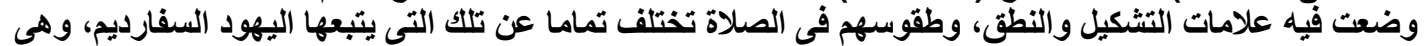
فى مجملها مأخوذة من مقتطفات من التوراة

"كاتت الفتيات الصغيرات والسيدات يرتدين ملابس العيد وقد غمرتهم بهجته، لقد كن يجلسن بعيدًا عن صحن الصلاة،

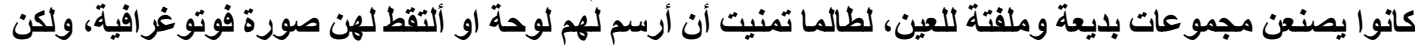

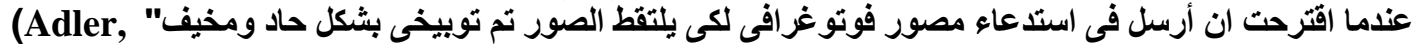

1905)

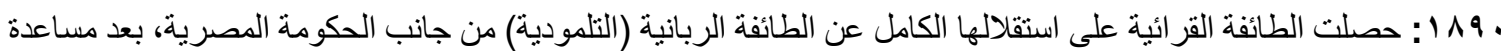

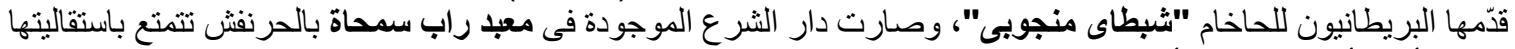

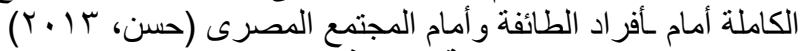

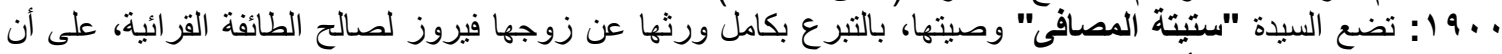

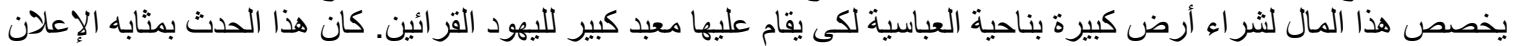

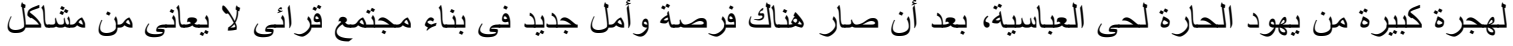

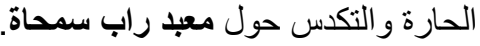
1 إ9 19: الطائفة القر ائية المصرية تجنمع فى معبد راب سمحاة وتضع اللائحة الداخلية لتنظيم الطائفة، وتقر قانون الطائفة كما

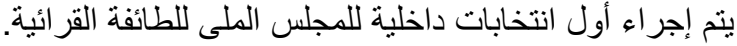

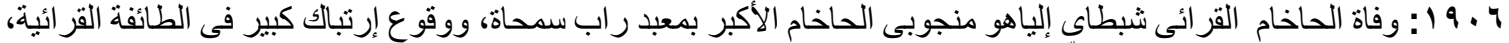

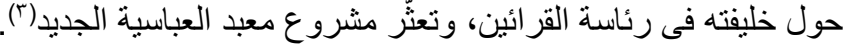

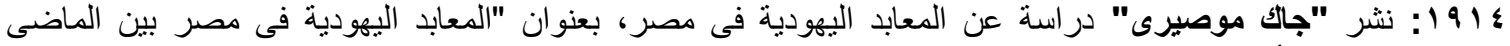

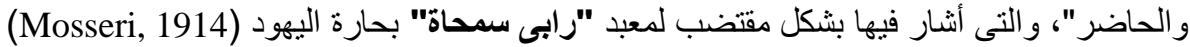

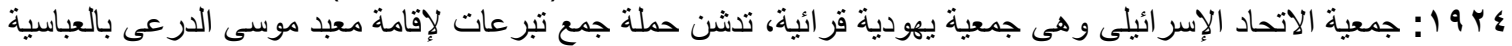

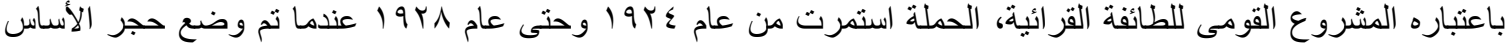

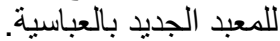

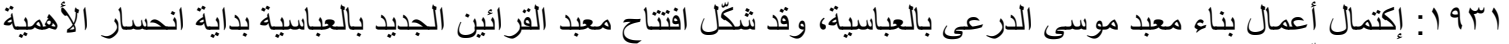

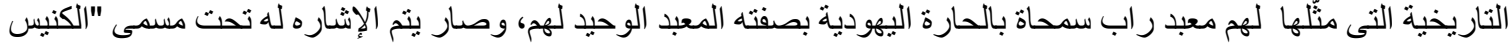

القديم" بينما معبد العباسية حمل لقب "الكنبس الكبير" (Outhwaite \& Bhayro, 2010)

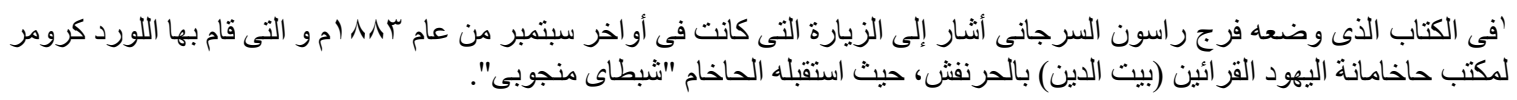
Murūd al-Qudsï: "The Karaite Jews of Egypt,".., USA,2nd Press 2006, P.69

r " " وكانت له علاقات طيب مع الحاكمين المصريين، توفيق و عباس حلمى، بل إنه كان صديقًا للورد كرومر" يوسف الجميل؛ اليهود

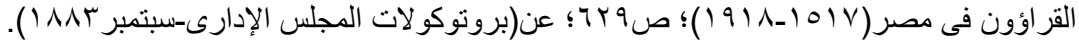

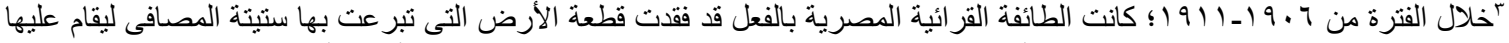

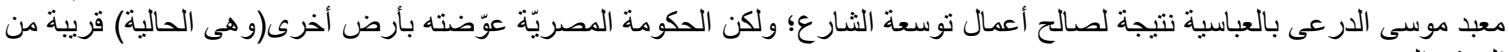
الموقع القيم. 


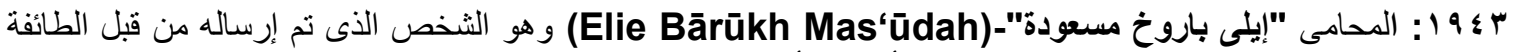

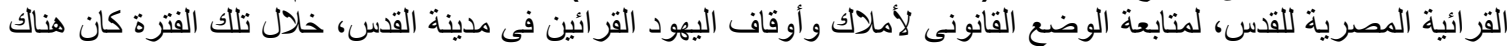

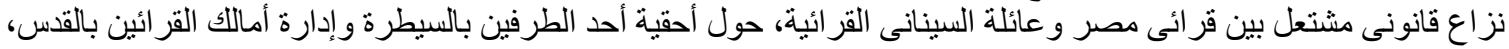

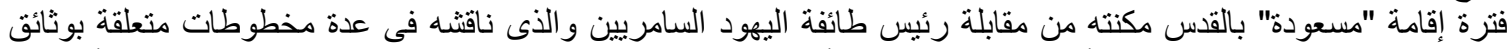

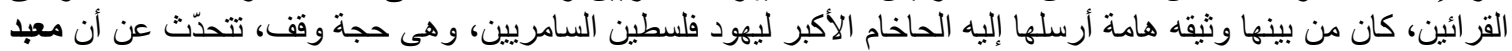

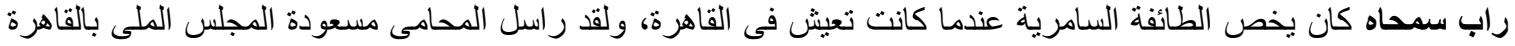

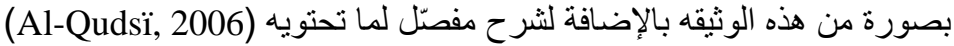

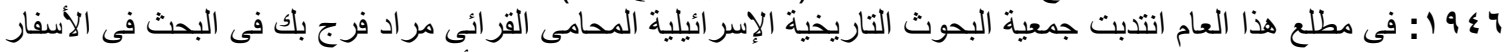

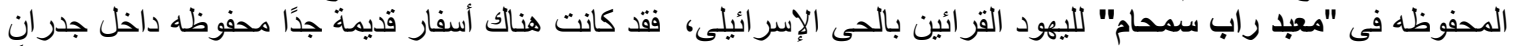

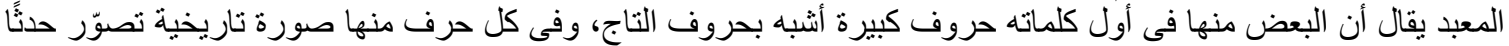

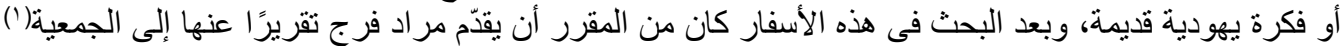

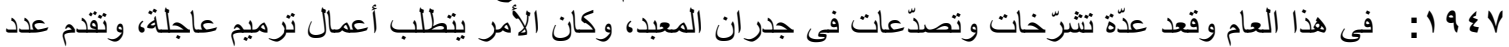

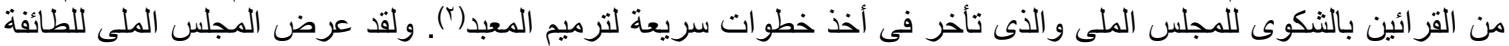

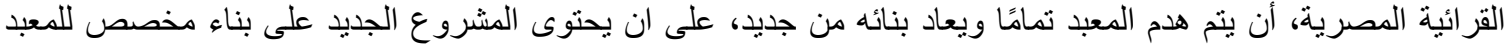

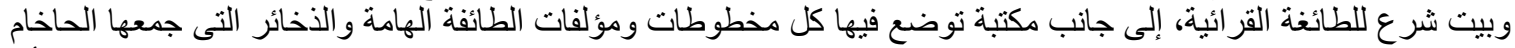

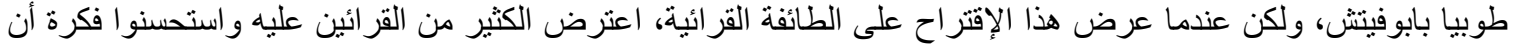

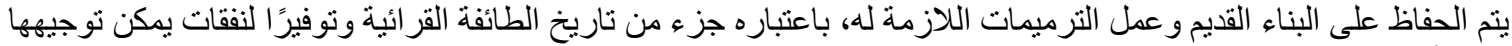

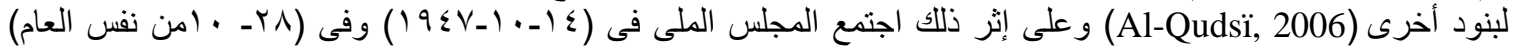

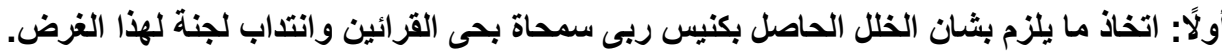

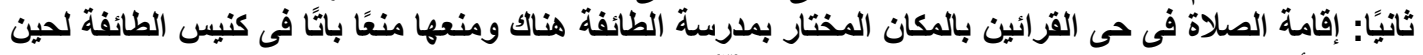

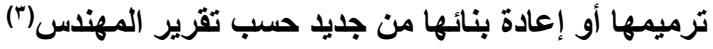

1 § 19 1: خلال هذا العام كانت أعمال التدعيم والتنكيس للمعبد تسبر على قدم وساق حيث تم تجديده، إلى جانب وقوع إنفجار

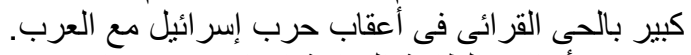

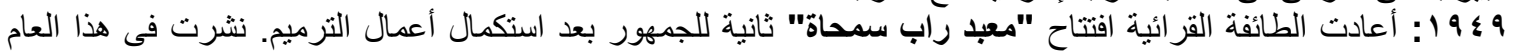

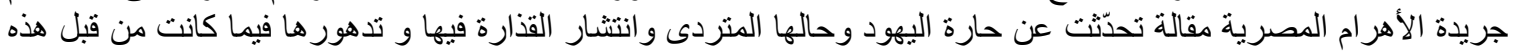

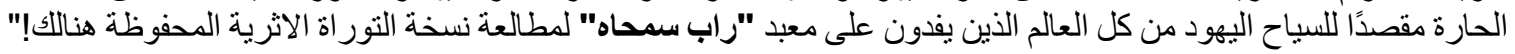

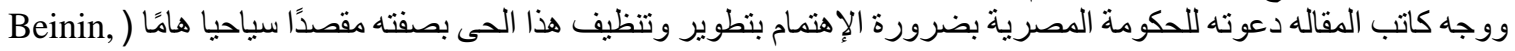

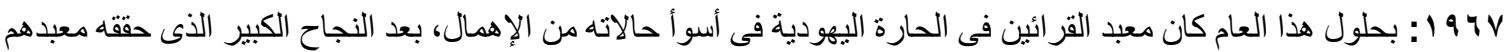

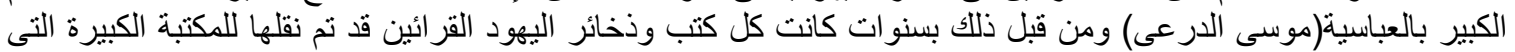

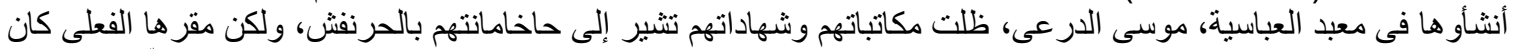

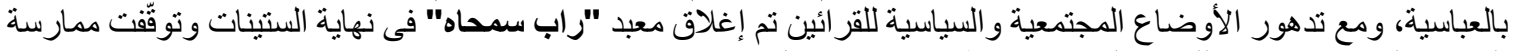

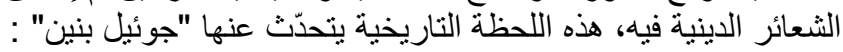

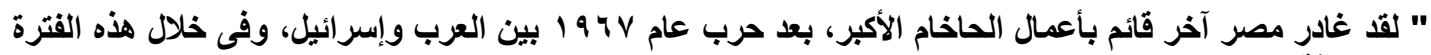

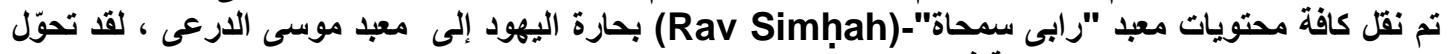

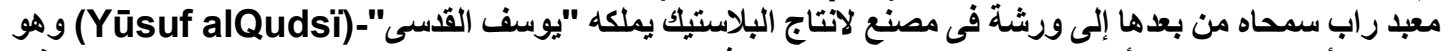

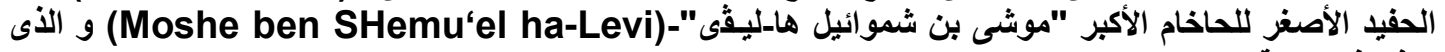

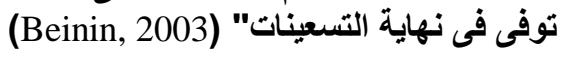

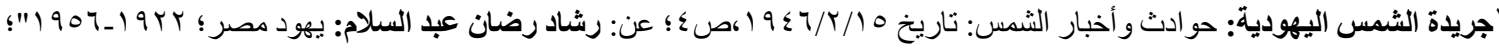

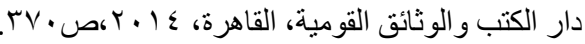

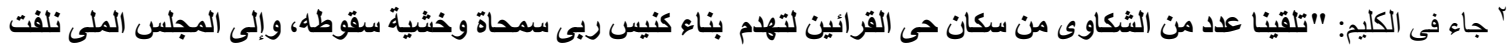

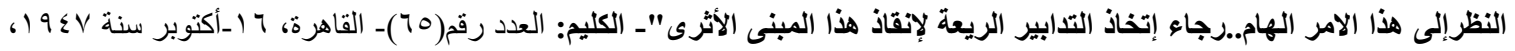




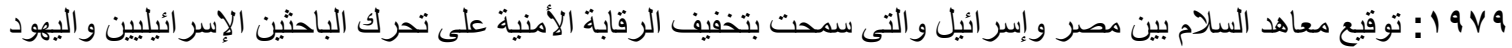

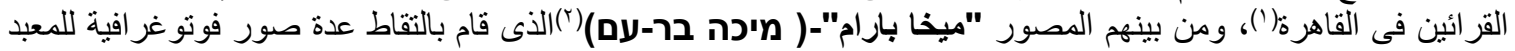

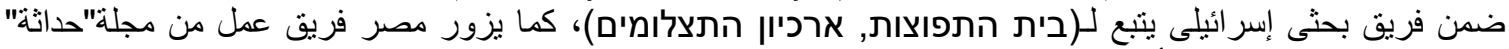
الإسر ائلية و يلتقى بعدد من أفر اد الطائفة القرائية فى معبد موسى الدرعى بالعباسية.

ب 191 ا : فى يوليو من هذا العام يزور "مراد القسى" القرائى وعضو المجلس الملى القاهرة ضمن رحله بحثيه لجمع تاريخ

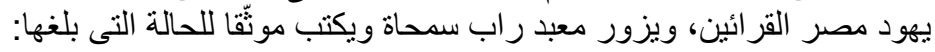

"اليوم صار معبد راب سمحاه عبارة عن ورشة مستخدمة من قبل مصنع للمنتجات البلاستيكية، تمتلكه سيّدة مسلمة،

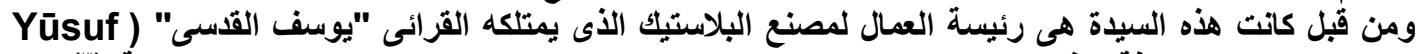

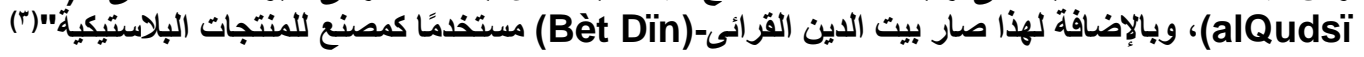

شكل (؛) الألواح الرخامية التى تعلو مدخل معبد راب سمحاة كما التقطتها عدة مراد القسى سنة بA19
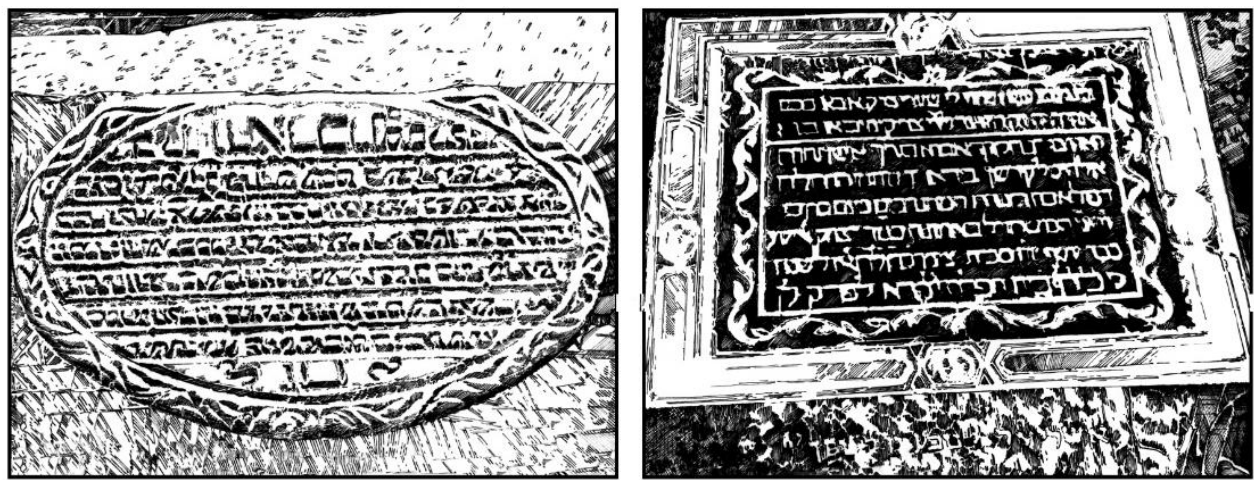

Rabi Simha Karaite Synagogue in 1982,

Engraved by the Author based on an old photograph by: Murūd al-Qudsï

ب 19 1 : السيدة كارمن و اينشتاين رئيسة الطائفة اليهودية المصرية تتقدم بطلب للحكومة لتسجيل كافة المعابد اليهودية كآثار،

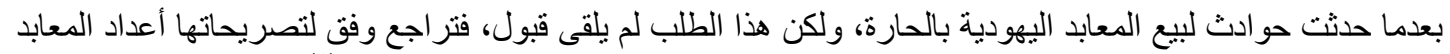

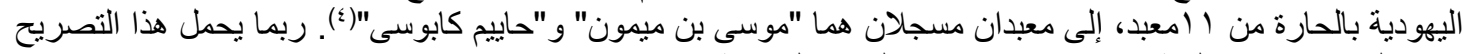

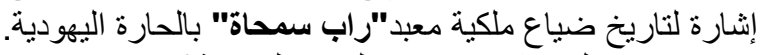

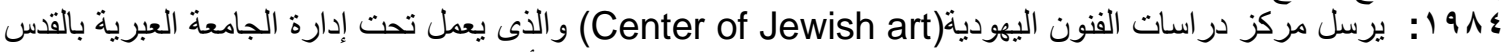

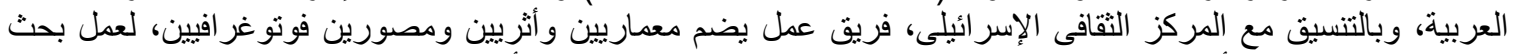

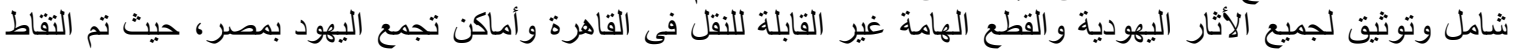

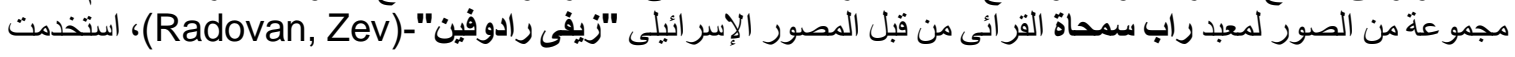

' "سمح توقيع اتفاقية السلام بين مصر وإسرائيل بوجود فرصة للسفير الإسرائليى لكى يساهم فى بناء مكتبة معبد موسى الارعى لليهود

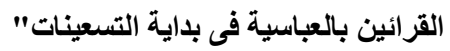

Joel Beinin: "The Karites in Modern Egypt" a chapter within abook, Edited by: Meira Polliack: Karaite Judaism: A Guide to Its History and Literary Sourcesm Brill, 2003,P423.

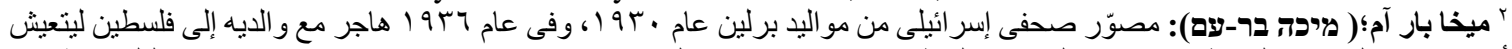

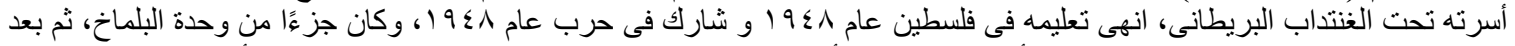

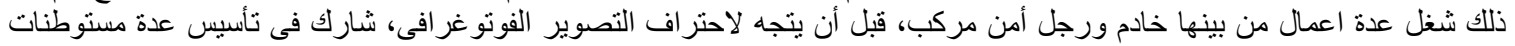

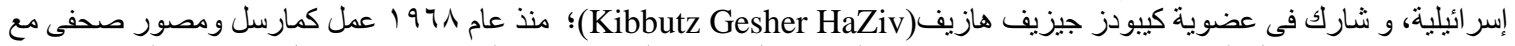

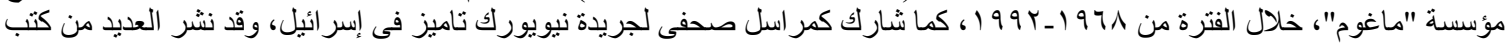

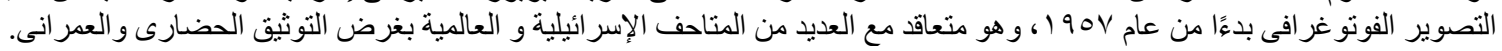
${ }^{3}$ Murūd al-Qudsï: "The Karaite Jews of Egypt, 1882-1986" , USA, Press 2006,P.124.

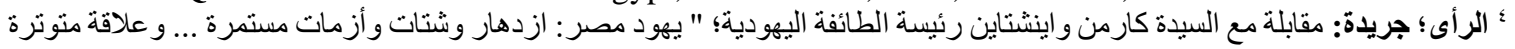

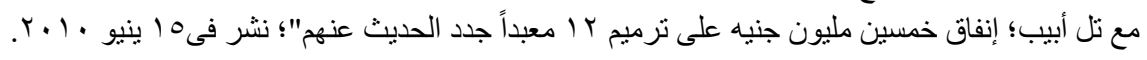




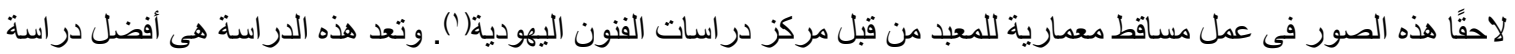

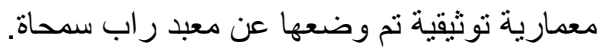

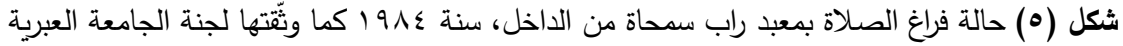

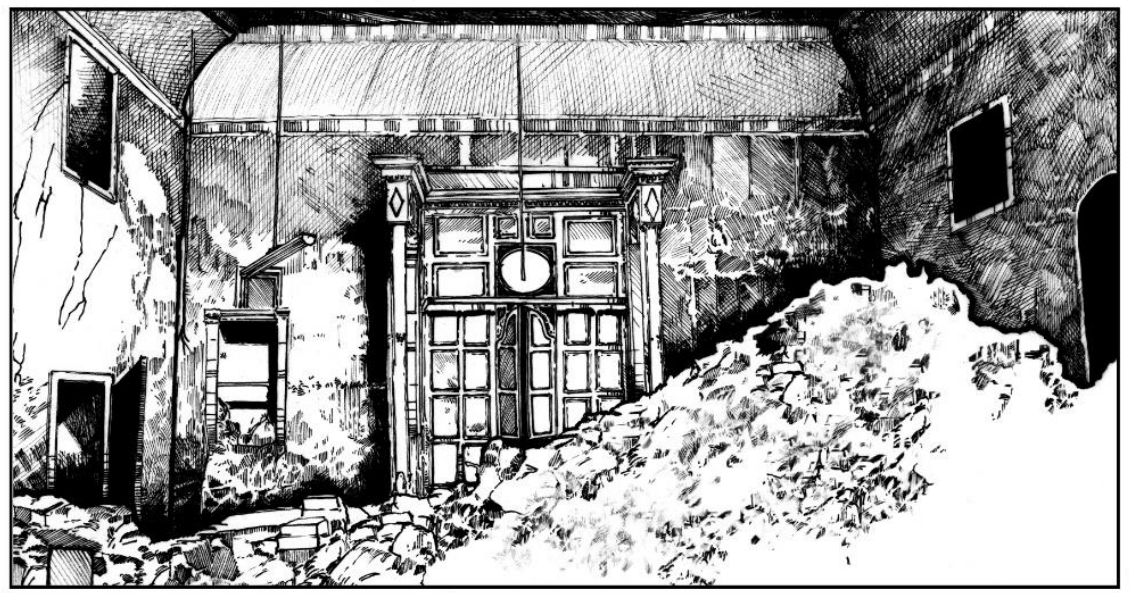

Rabi Simha Karaite Synagogue in 1984, Engraved by the Author based on an old photograph by: Radovan, Zev

\ 9 ا : الباحث الإسر ائيلى "جثوا هايزنبرج" و المتخصص فى در اسات الموسيقى اليهودية، يسافر للو لايات المتحدة الامريكية

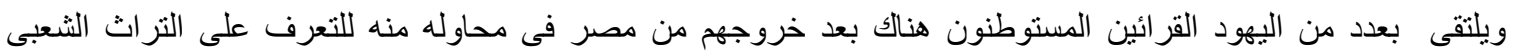

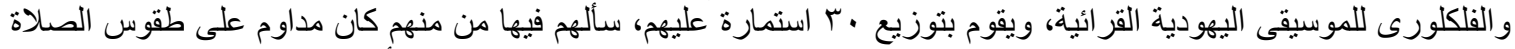
اليومية بمعبد "دار سمحاة"-(the Dar Simha synagogue) بحارة اليهود القرائين؟أربعة فقط من بين العينة البحثية

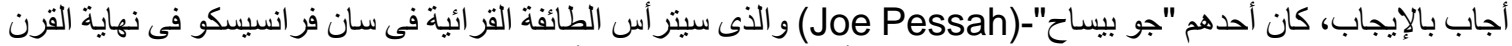

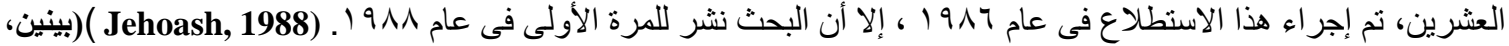

ر 19VV : في هذا العام قام "مراد القدسى" بنشر كتابه الأول عن تاريخ الطائفة القرائية المصرية والذى تعرّض فيه بشكل كبير لتاريخ معبد

راب سمحاه(r) (r)

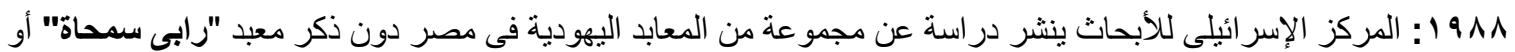

تاريخه بشكل مفصنّ. (Cassuto, D., 1988)

9 9 1 : ينشر الباحث "عرفه عبده على" مقالة عن المعابد اليهودية المصرية، و التى استتد فى بعض نقاطها للار اسة الإسر ائيلية

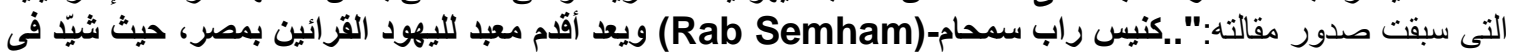

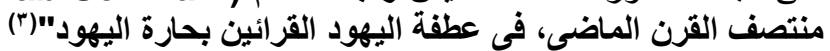

ا 99 1: كتب النبوى سر اج در اسة عن المعابد اليهودية المصرية، والتى تضدنت إثـار ات مقتضبة لمعبد رابى سمحاة بحارة

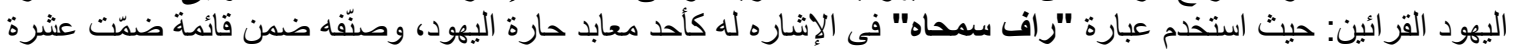

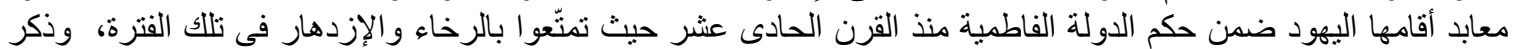

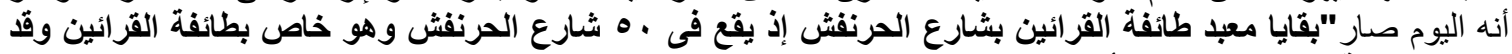

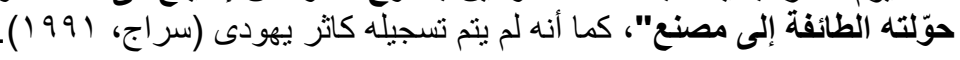

1 The Bezalel Narkiss Index of Jewish Art, with association of the Hebrew university of Jerusalem, Rav Semham synagogue) in Cairom 1984, Drawings of the Karaite Synagogue (Rav Semham synagogue) in Cairo, Cairo, 1864, ID: (21014-209109-209111-209113

r الدر اسة التى عرض لها مر اد القدىى تم إدماجها داخل السيرة التاريخية لمعبد راب سمحاة؛ كما تم الغشارة لها في الدر اسات السابقة القر ائية.

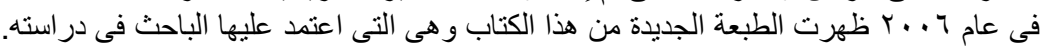
Murūd al-Qudsï: "The Karaite Jews of Egypt, 1882-1986" , USA, Press 2006.

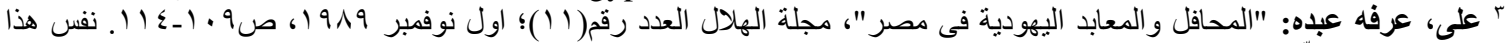

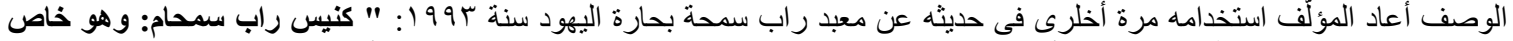

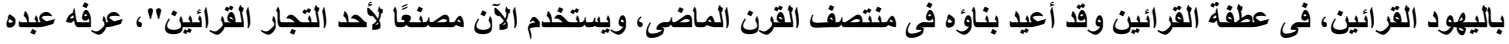

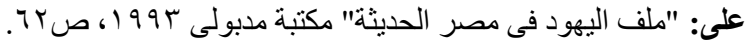




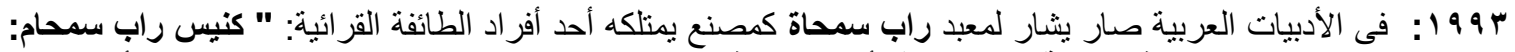

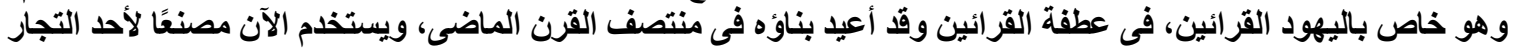

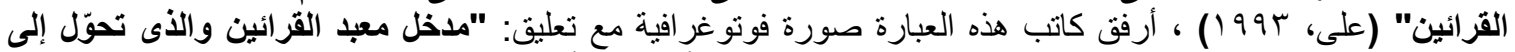

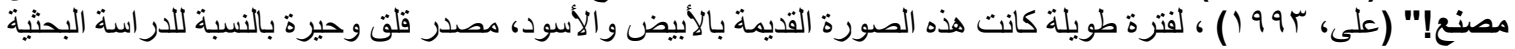

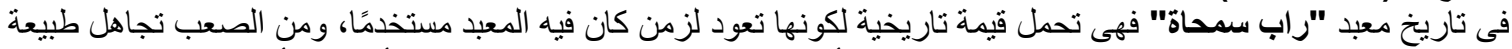

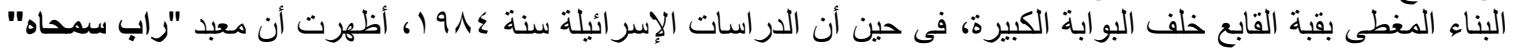

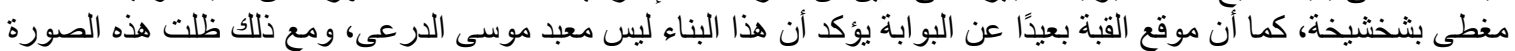

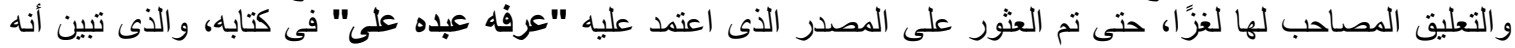

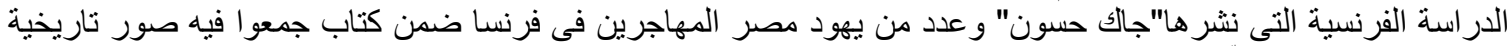

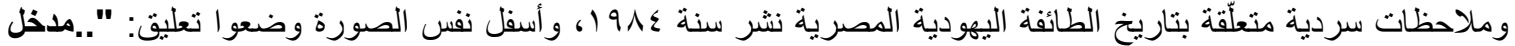
معبد طائفة اليهود القرائين والذى يعود للقرن الثامن عشر الميلادى (بحارة اليهود القرائين)، ولقد تحوّل هذئ هذا المعبد اليوم

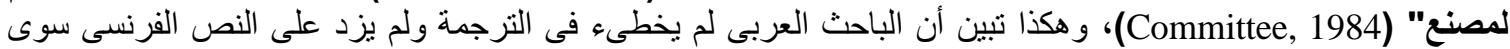

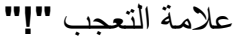

الصورة التى عرضها: جاك حسون وجماعة من يهود المهجر

الفرنسى ونسبوها إلى بوابة معبد راب سمحاه بحارة اليهود القرائين

ASPCJE Committee

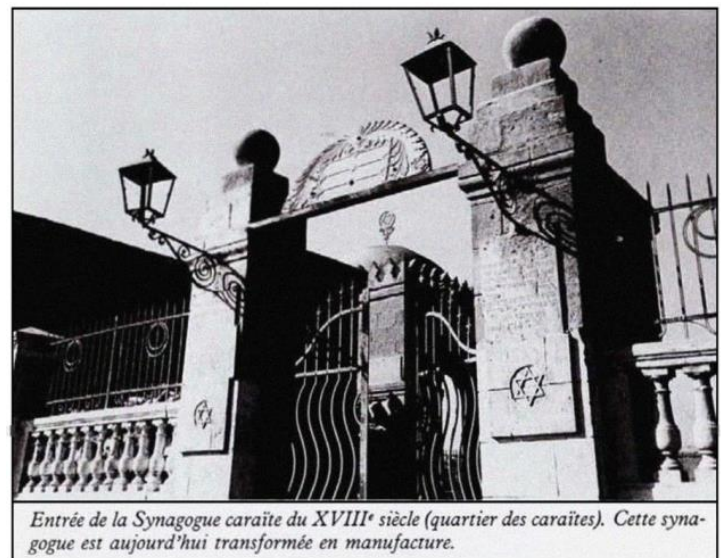

"Juifs d'Égypte:Images et textes",2nd ed. (Paris:

Editions du Scribe, 1984),P.140.
الصورة التى عرضها: عرفه عبده فى كتابه عن يهود مصر سنة

ب9 19 ، ونسبها إلى بوابة معبد راب سمحاه بحارة اليهود القرائين

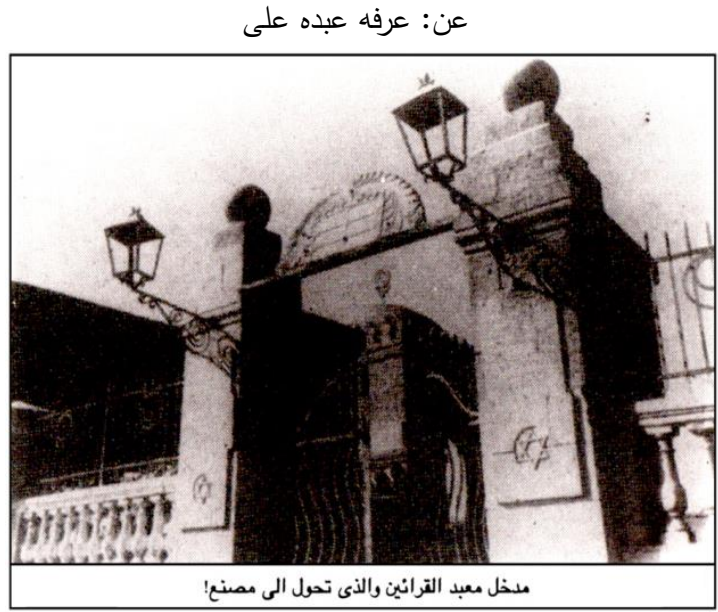

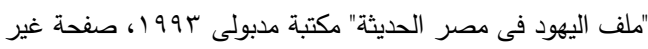

مرقومة ضمن ملحق الصور • مانه

ظلت هذه البو ابة المحيرة و الصورة الفوتوغر افية الغامضة التى تتسب لمعبد راب سمحاة وحارة اليهود القرائين، مصدر حيرة

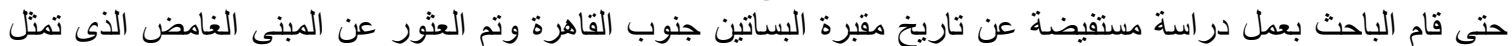

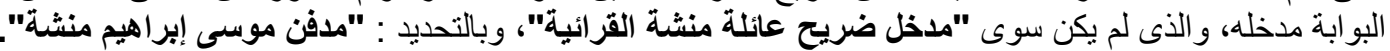
شكل (؟) مدخل ضريح عائلة اليهودى القرّائى: "موسى إبراهيم منشة" بمقابر البساتين جنوب القاهرة

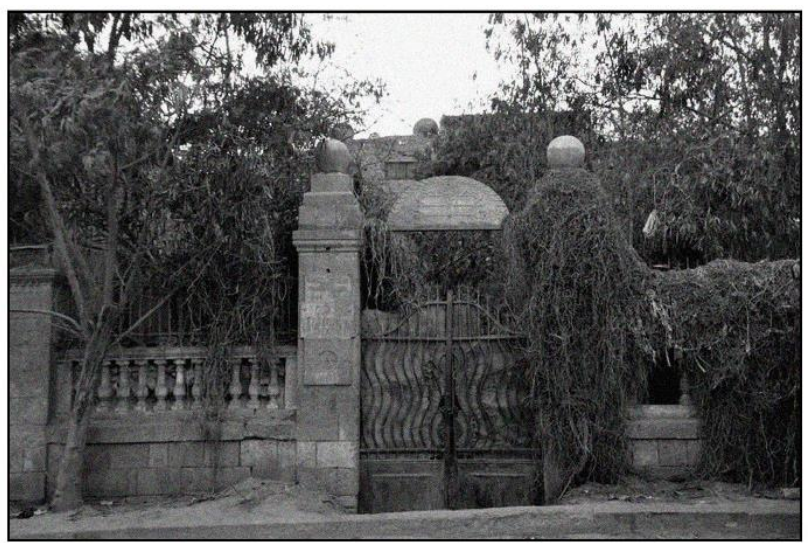

A photograph taken in 2018 by: D.Mostafa sadek 
؛ 9 1 : يو سف القدسى القائم بأعمال رئيس الطائفة اليهودية القرائية بمصر ينشط فى محاولة أخيرة للحفاظ على التراث الباقى

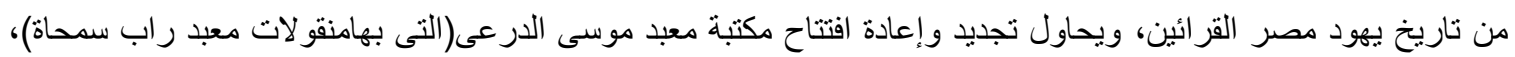
بمساعدة عدد من بهود إسر ائيل القرائين.

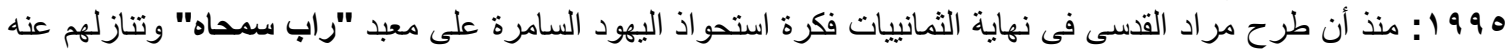

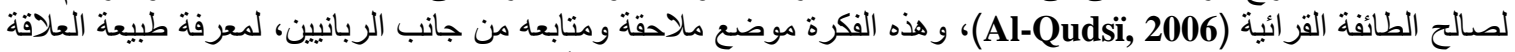

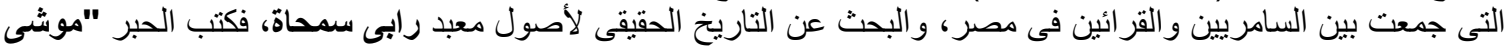

ي.كونيشويسكى":(Moshe. Y. Koniuchowsky):

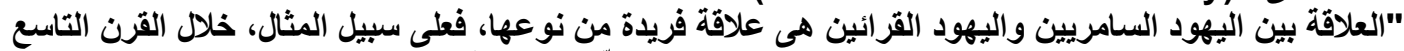

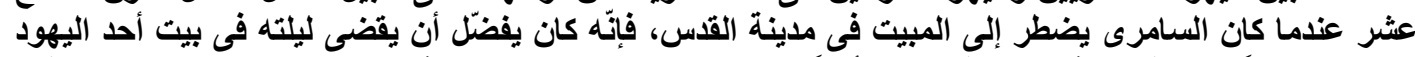

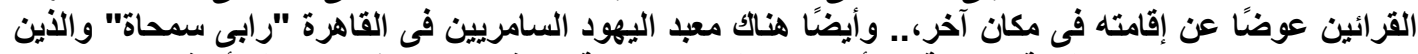

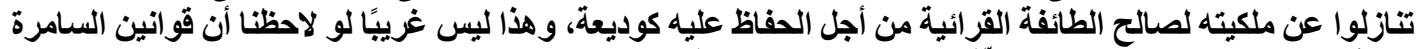

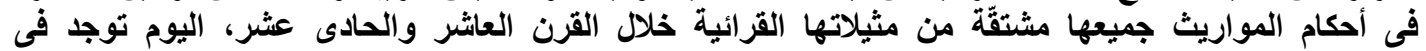

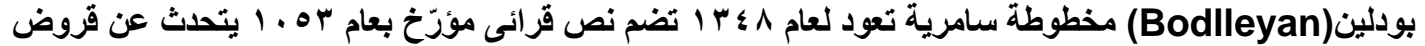
بين اليهود السامريين والقرائين فى قاهرة العصور الوسطى" (Rabbi, 1995)

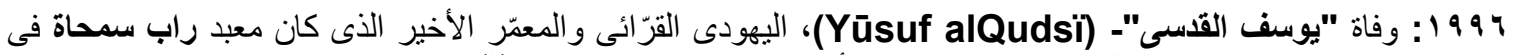

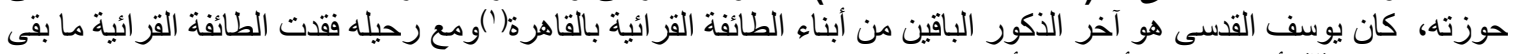
لها من استقلال(r) أصبحت كل أملاكها وأوقافها تتبع الطائفة اليهودية الربانية الطنة بالقاهرة من الناحية الإدارية.

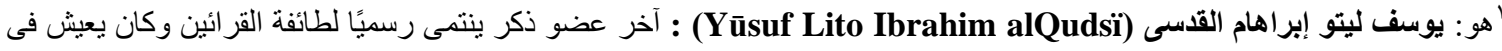

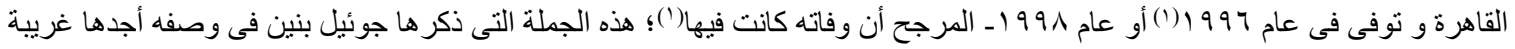

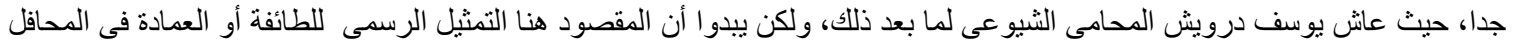

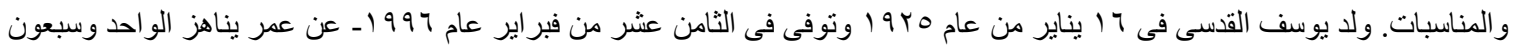

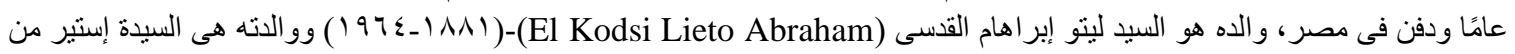

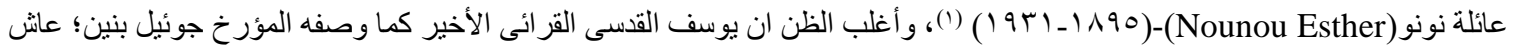

$$
\text { وحيذًا ومات وحيدًا. }
$$

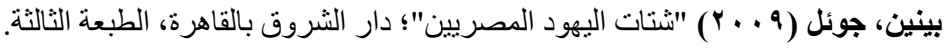

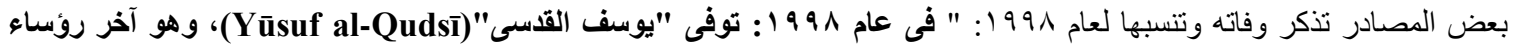

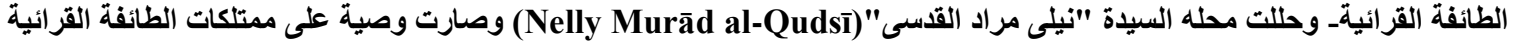

الباقية فى مصر ولكنها لم تعمر كثيرًا من بعده."

Al-Qudsï Murūd (2006) "The Karaite Jews of Egypt, 1882-1986), USA,2nd Press, P.87.

The Karaite Families, after: Farhi Orgnization, ID: I1 150 , F197, updated 3 Jun 2014.

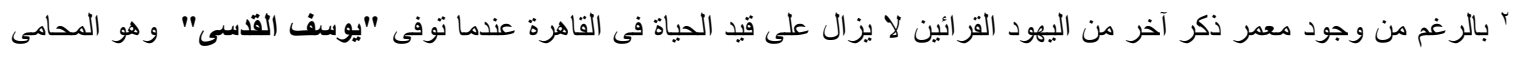

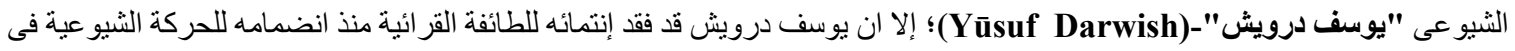
نهاية الثلاثينات من القرن الماضى.

Joel Beinin: "The Karites in Modern Egypt" a chapter within abook, Edited by: Meira Polliack: Karaite Judaism: A Guide to Its History and Literary Sourcesm Brill, 2003,P423. 


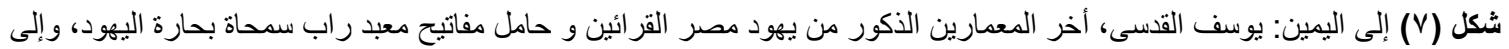

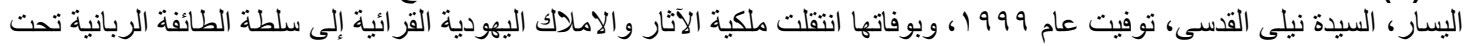

قيادة السيدة "كارمن جولدشتاين"، ومن بعدها "ماجدة هارون".
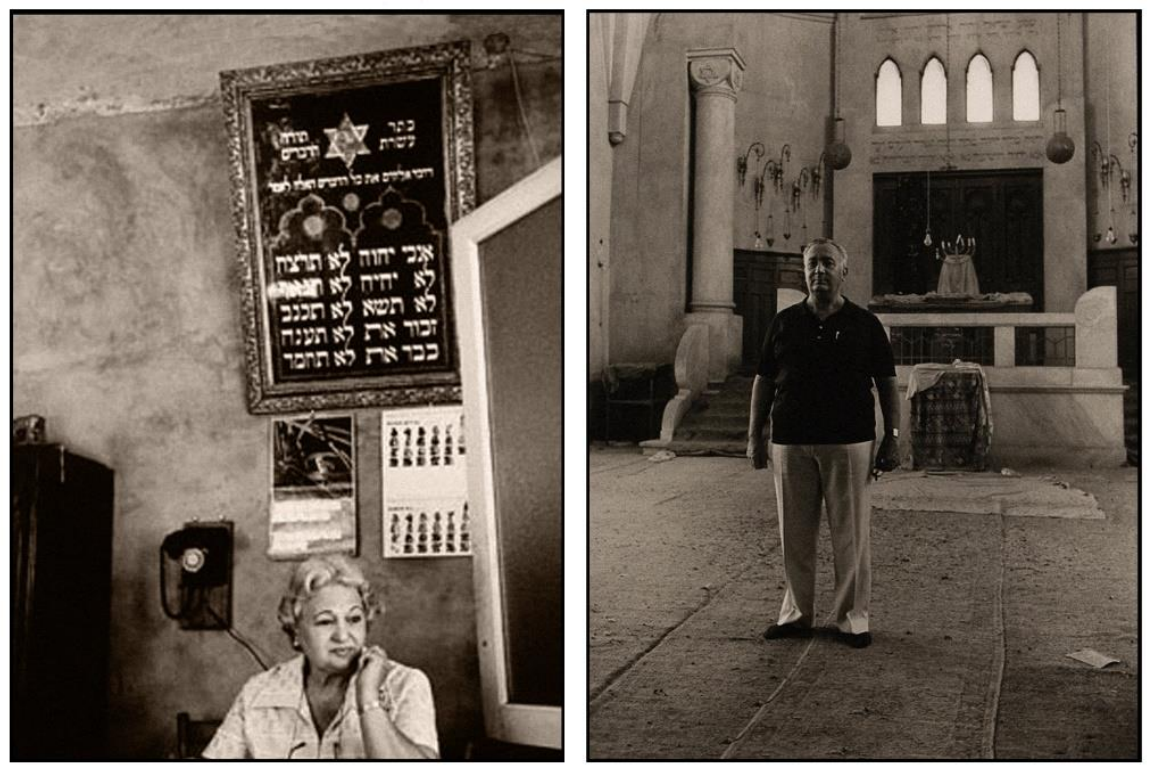

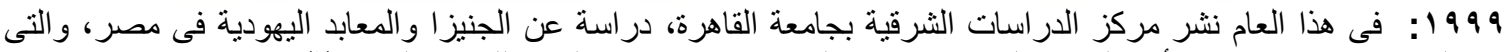

تجاهلت معبد راب سمحاه كأحد المبانى القائمة واكتفت بالحديث عن تاريخه بالنسبة للطائفة القر ائية (1).

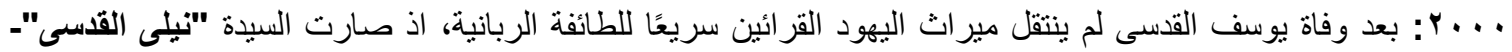
(Nelly Murād al-Qudsī)

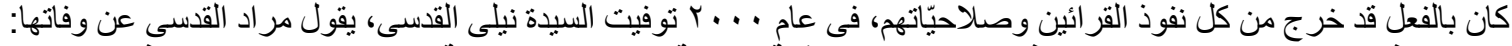

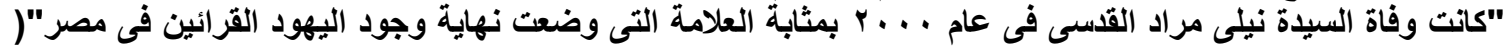

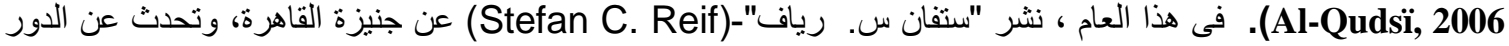

الكبير الذى لعبته مكتبة معبد راب سمحاه في الكثف عن تراث اليهود القرائين خلال العصور الوسطى(Reif, 2000)

ץ . . ץ : ينشر "مراد القدسى" كتابه عن ناريخ يهود مصر القرائين ، بعنوان "حتى لا نتسى" والذى احتوى على لمحة

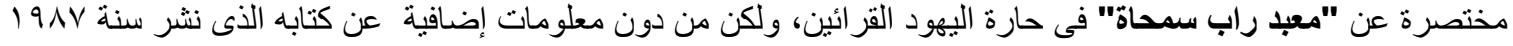
(Al-Qudsï, 2002) ضمن الدراسة التى وضعها كل من "إلكان ز." و"م. بن ساد ساسون" عن الجنيزة القاهرية بمعبد راب سمحاة بحارة اليهود

(Elkin, 2000)

ץ + . ץ:يتم الإشارة للمعبد ومكتبته القرائية النادرة فى أحد الدراسات التى تناولت الجنيزة القاهرية:

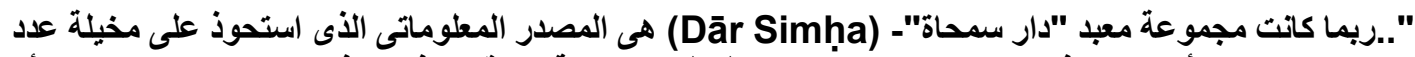

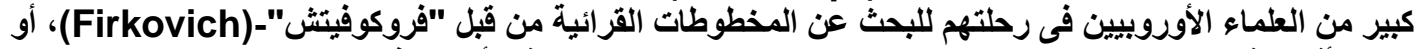

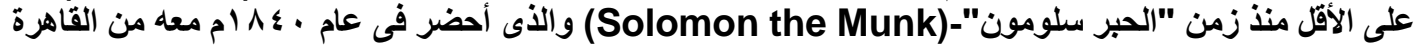
مجموعة كبيرة من المخطوطات القرائية والتى أودعها في المكتبة الوطنية فى باريس" (D.Sklare, 2003). ع . . ץ : فى السادس من مايو منه تنشط جمعية النبى دانيال(Nebi Daniel association) و التى يدير ها يهود الإسكندرية فى محاولة لتوثيق التراث المعمارى لمعابد القاهرة والإسكندرية بالتعاون مع السيدة كارمن و اينشتاين، لعرض فكرة عمل خطة

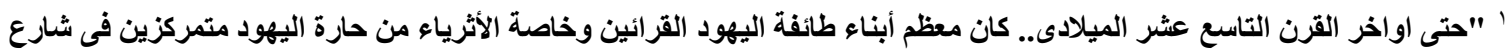

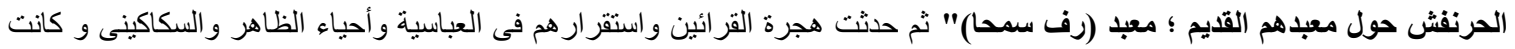

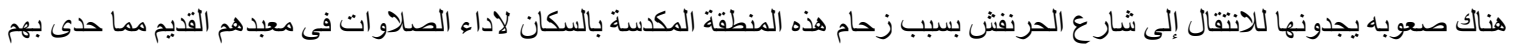

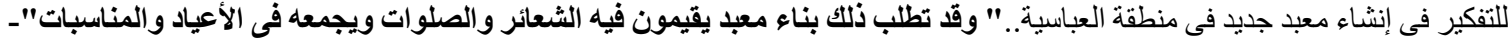

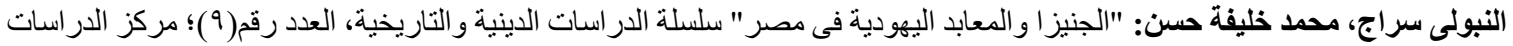

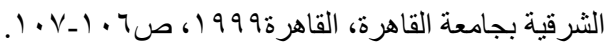




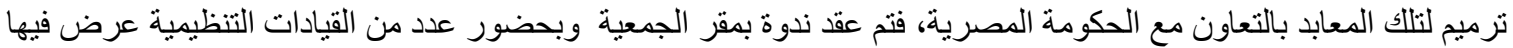

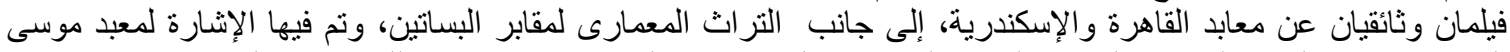

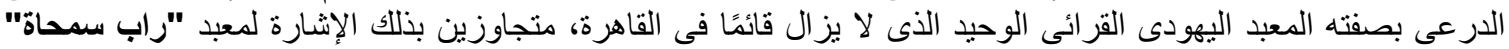

(Daniel, 2004)

ه . . ץ: جوئيل بنين يشير في كتابه "شتات اليهود المصريين" لمعبد راب سمحاه، باعتباره المكان الذى اعتاد "جو بيساح"-

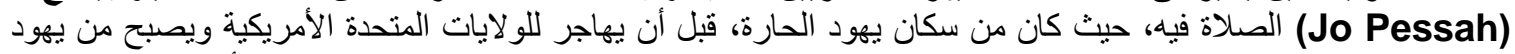

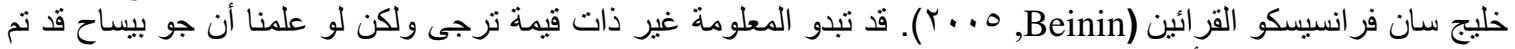

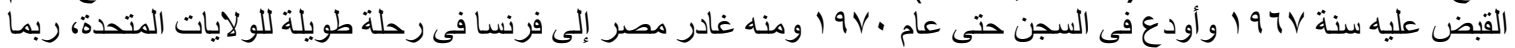

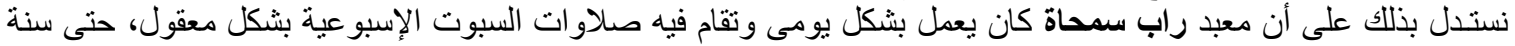

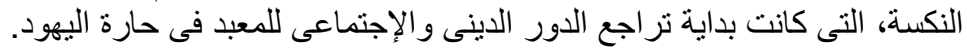

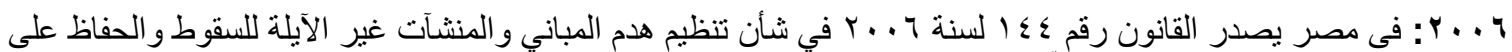

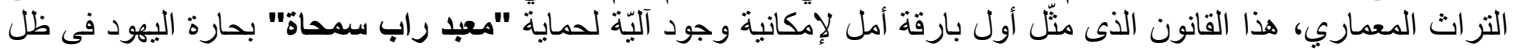

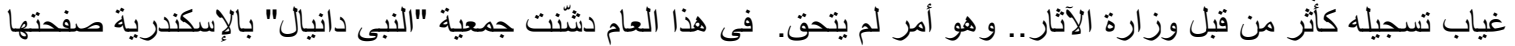

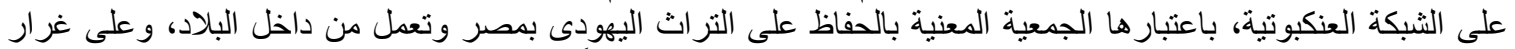

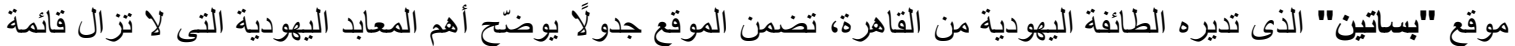

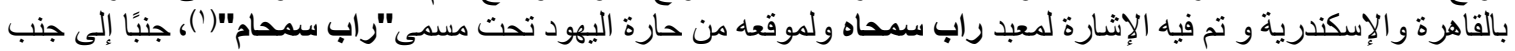

$$
\text { مع كنيس اليهود القر ائين بالعباسية ، موسى الإنيارة لمعبد الدرعى. }
$$

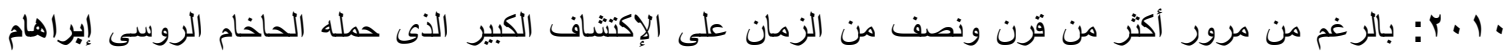

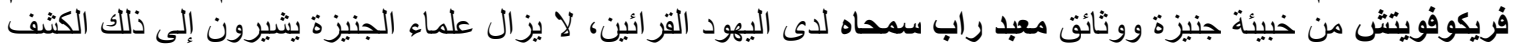

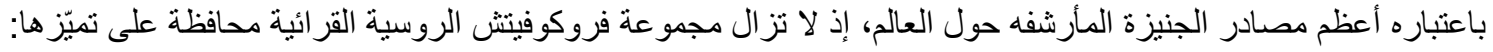

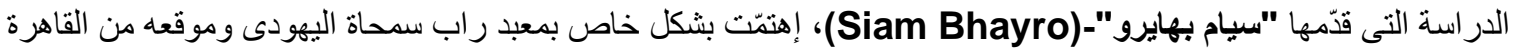

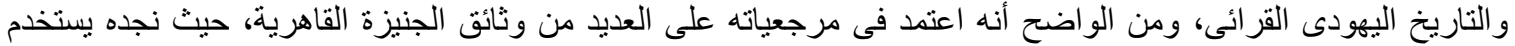
"لفظة "دار سمحاة" وليس "راب سمحاة"، حيث بالفعل كان يطلق على هذا المعبد خلال فترة العصور الوسطى لفظة "دار":

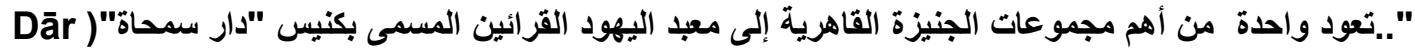

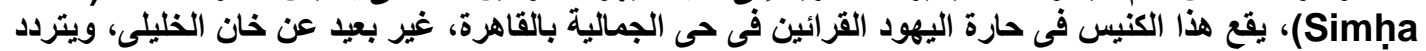

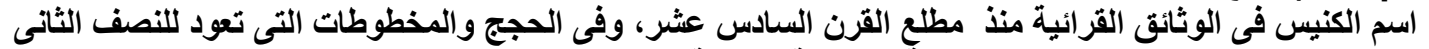

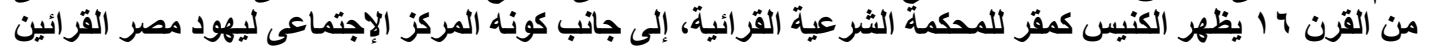

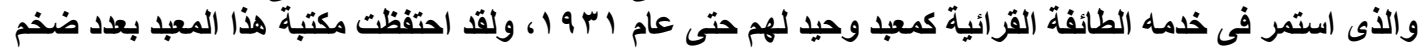

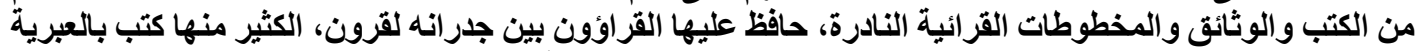

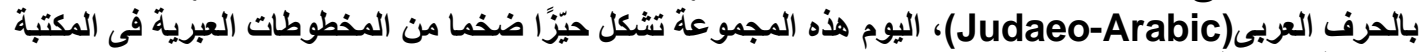

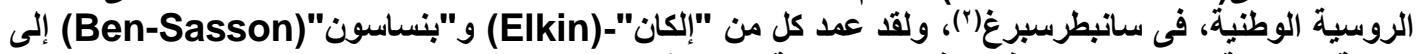

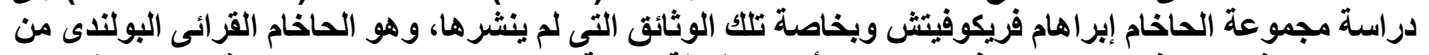

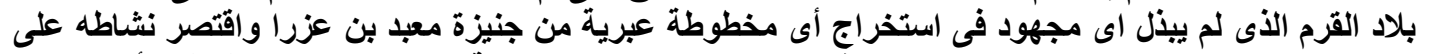

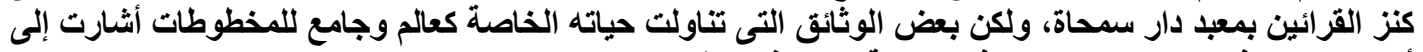

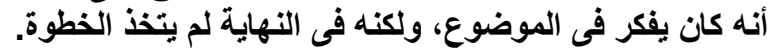

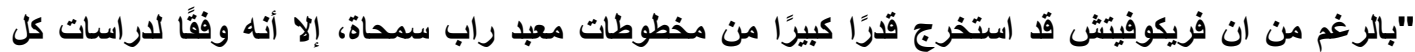

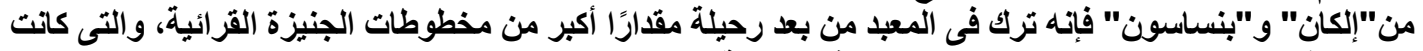

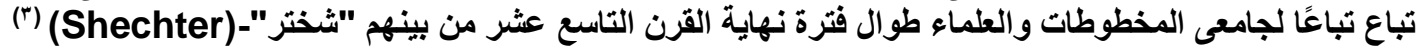

${ }^{1}$ Rab Semham, Hart El Yahoud - Caraïte, Nebi Daniel association in Alexandria :" Synagogues de Le Egypte" Published on line at: (http://www.nebidaniel.org) on 2006m revised on 2019.

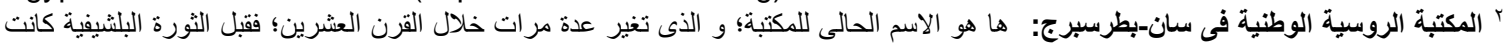

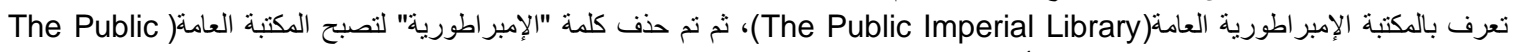

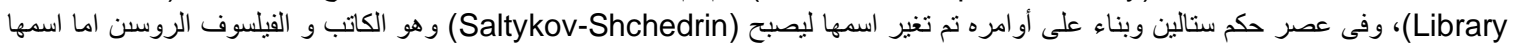

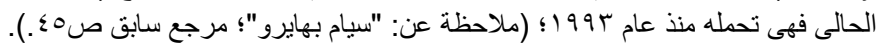

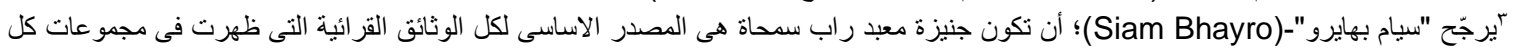

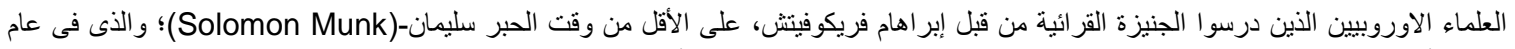

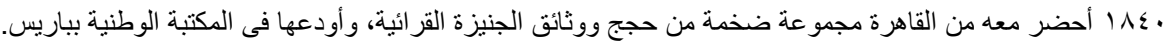




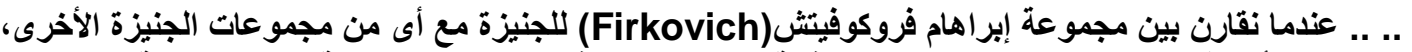

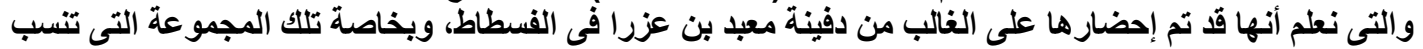

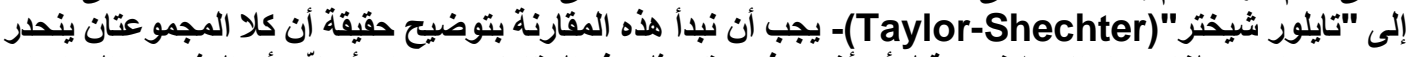

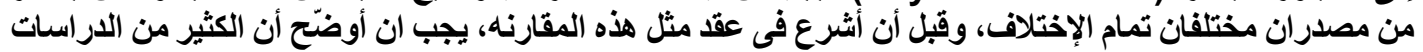

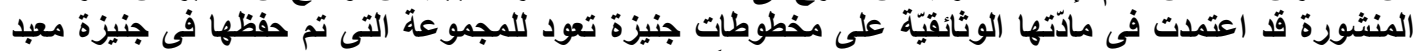

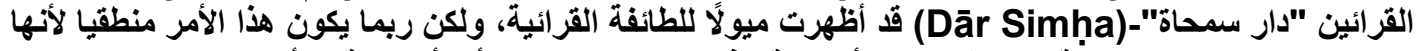

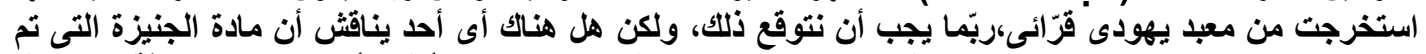

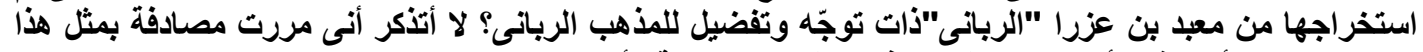

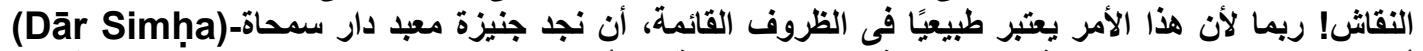

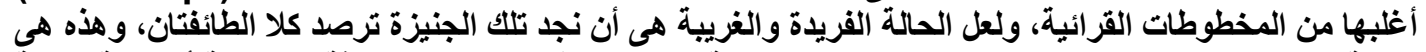

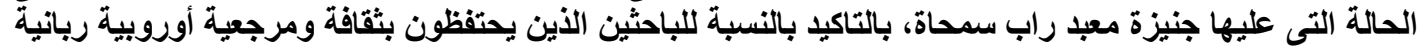

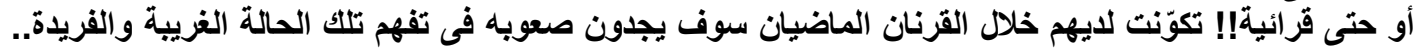

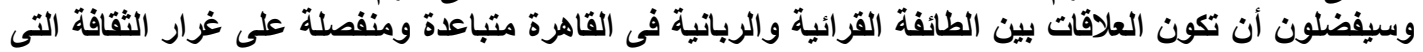

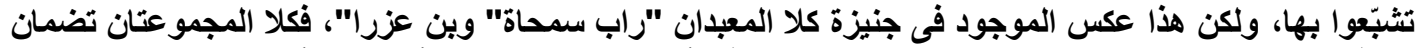

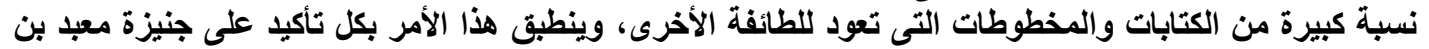

عزرا..." (Outhwaite \& Bhayro, 2010)

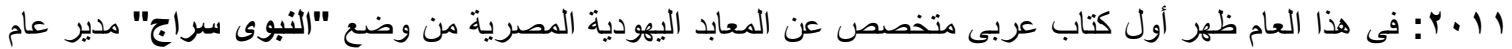

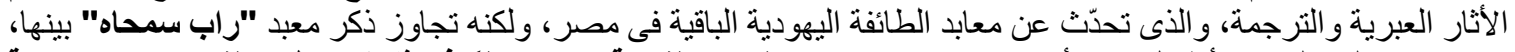

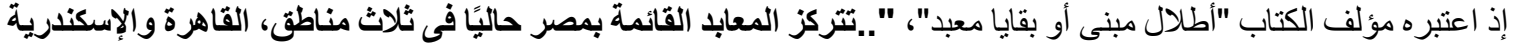

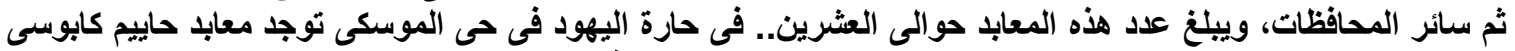

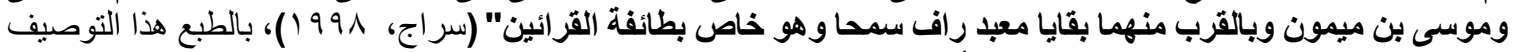
الخطر ينذر بزوال كنيس راب سمحاه على الأقل من دائرة إهتمام المعنيين و المهتمين بالآثار اليهودية فئ مصرئ

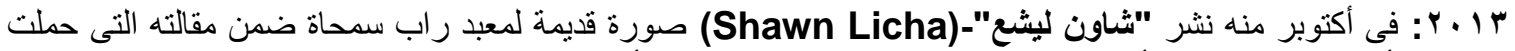

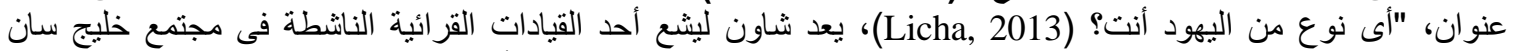

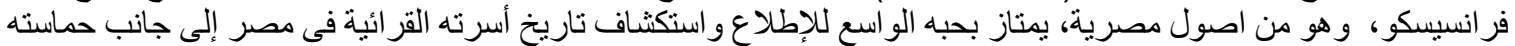

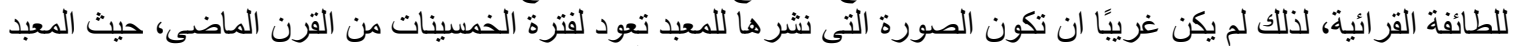

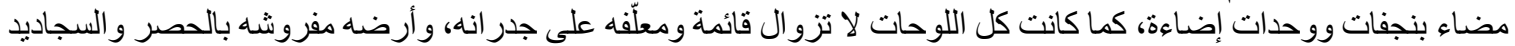

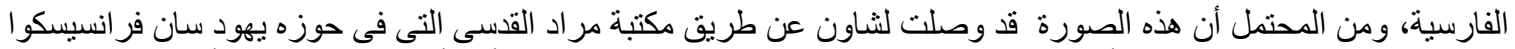

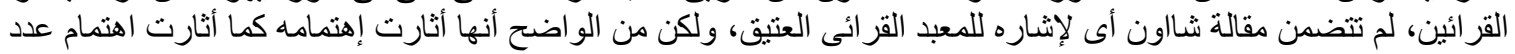
آخر من القرائين.

D.Sklare: "A Guide to Collections of karaite Manuscripts", in M.Polliak (ed.);"Karaite Judaism: a guide to its history and Literary Sources", Leiden, Press2003, PP.893-924 (894). Ben Outhwaite, Siam Bhayro: "From a Sacred Source": Genizah Studies in Honour of Professor Stefan C. Reif. Cambridge Genizah Studies Series", BRILL,Press2010,Pp44-45. 
شكل (^) معبد راب سمحاة بحارة اليهود، صورة تعود لفترة الأربعينات أو الخمسينات، عندما كان المعبد فى كامل زينته وتألقه،

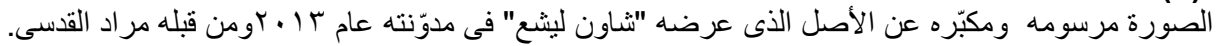

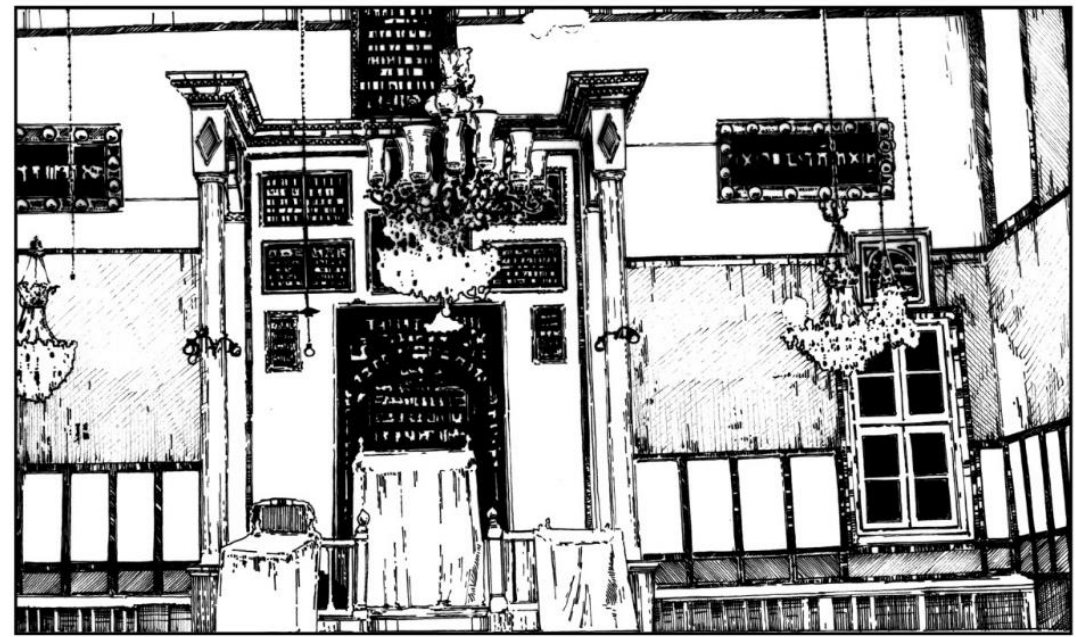

Rabi Simha Karaite Synagogue in 40s or 50s, Engraved by the Author based on an old photograph

فى مطلع الثهر التالى من نفس العام ، وفى ضوء الصورة التى نشرها شاون، الذى صدار بر اسل شخصية فى القاهرة، راسلته

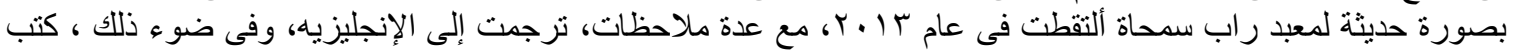

"..يبدو أنتى فى كل مرة أقدم نسخة هدية من كتاب مراد القدسى لأحدهم، يحدث أن يكتشف أو تكتثف شيئًا ما متميّزا

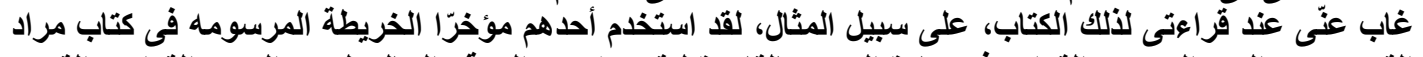

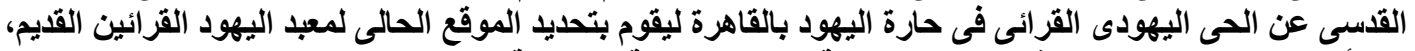

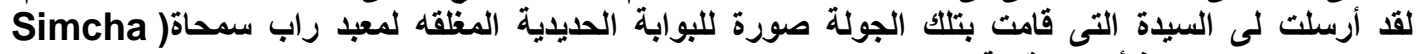

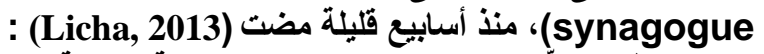

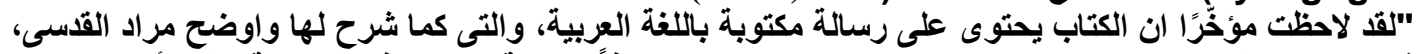

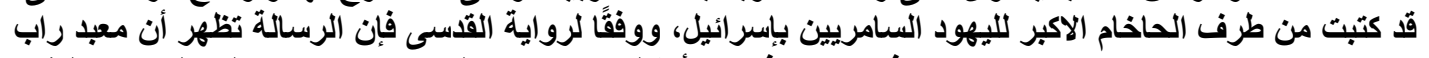

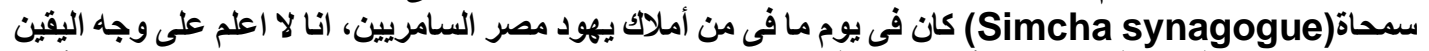

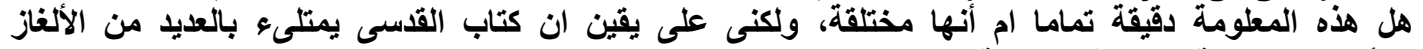

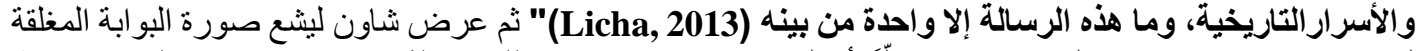

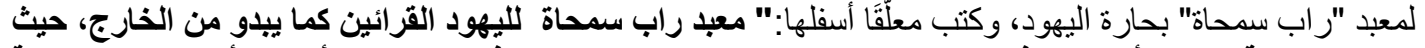

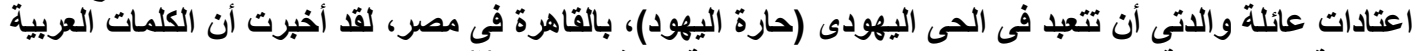

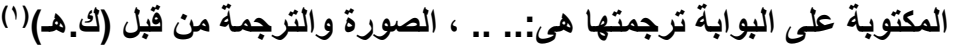

$$
\begin{aligned}
& \text { شكل (9) البوابة الخارجية لمعبد راب سمحاه عن صورة فوتوغرافية إلتقطت لها فى نهاية عام ب ا ـ } \\
& \text { كتب عليها بالعربية، بخط ابيض مميز على خلفية من الحديد الصدىء: }
\end{aligned}
$$

1 "Exterior of the Simcha Karaite synagogue, where my mom's family worshiped in Jewish Quarter of Cairo, Egypt. I'm told the Arabic reads: “Important Notice. This property is listed architectural heritage: Jewish synagogue. The sale or rental of the property, or any other use for profit, is forbidden." (Photo \& Translation by K.H.)", After: Shawn Licha: on 3 Oct 2013. 


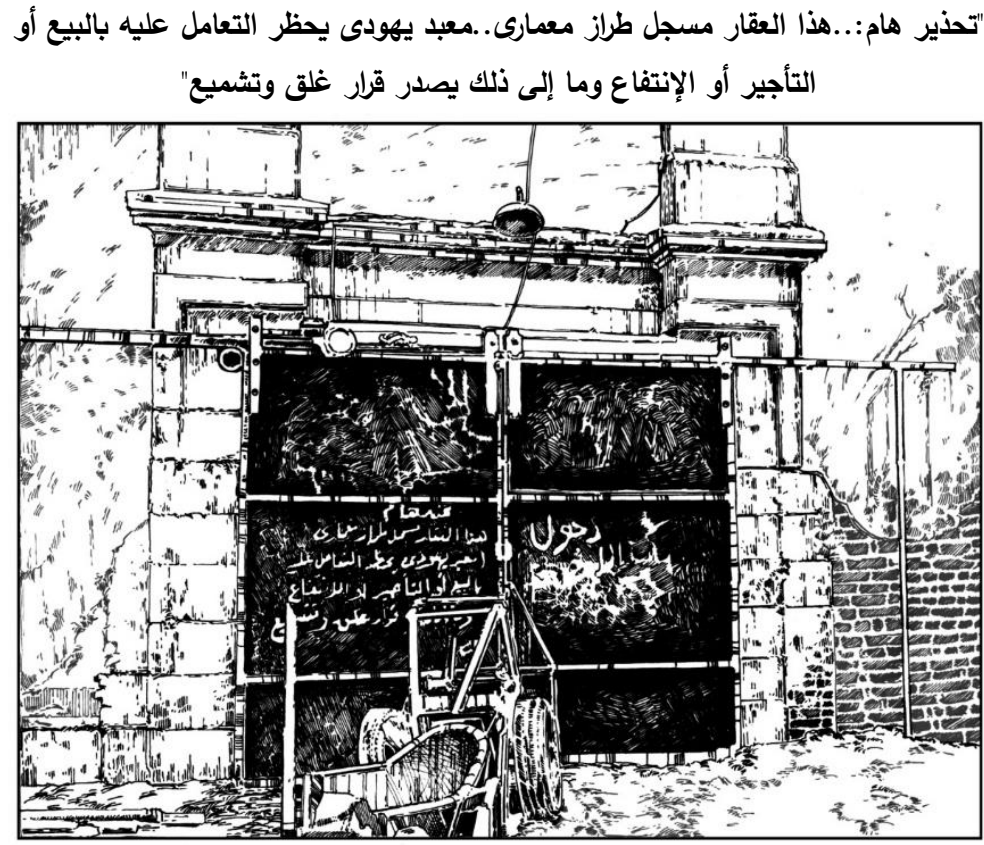

Rabi Simha Karaite Synagogue 's Gate in 2013,

Engraved by the Author based on modern Photo taken By K.H.

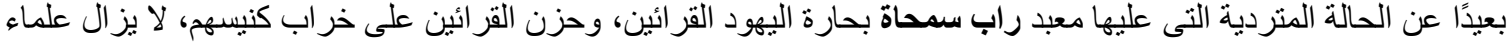

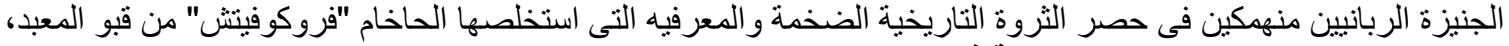

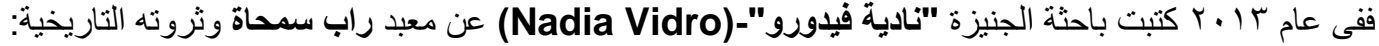

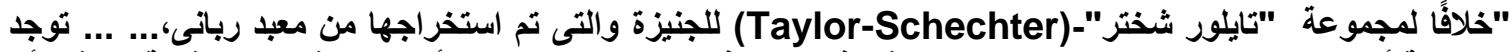

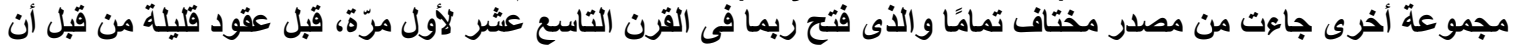

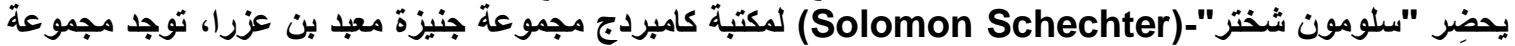

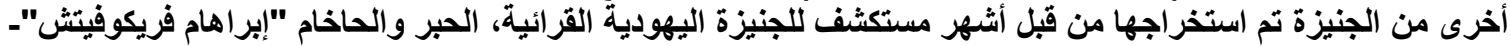

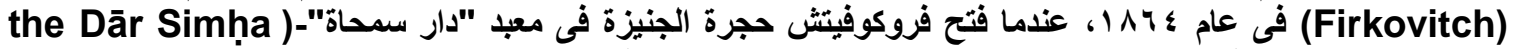
(Synagogue والذى كان المعبد الرئيسى لليهود القرائين بالقاهرة وقتتها.

تعد محتويات هذا الكنز من الجنيزة أهم مصدر معروف فى تاريخ الجنيزة القرائية، والذى يحمل اسم " مجموعة الجنيزة

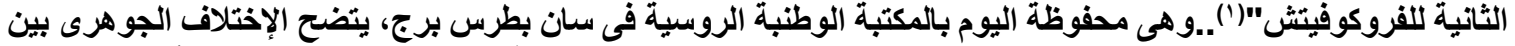

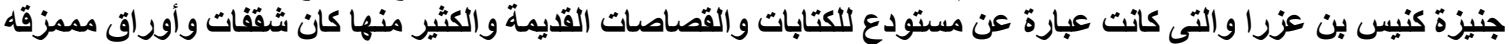

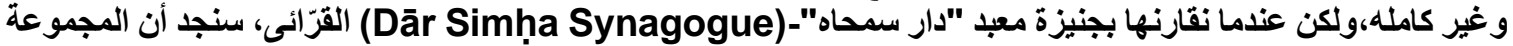

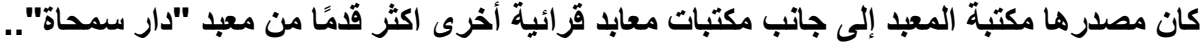

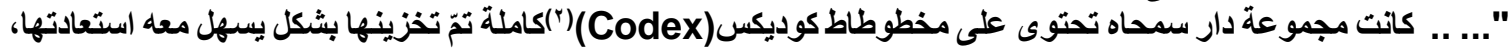

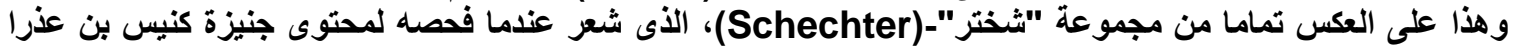

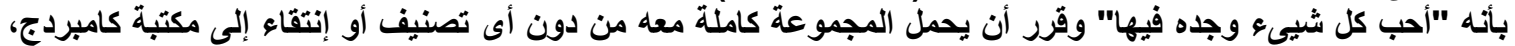

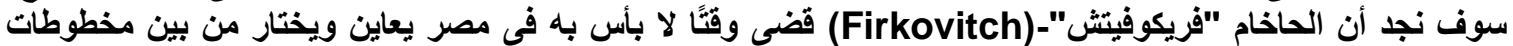

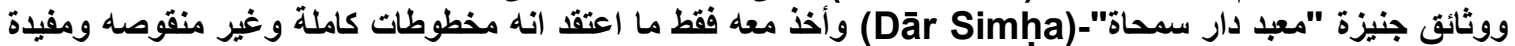
لاراسته فى تاريخ اليهود القرائين"

${ }^{1}$ The second Firkovitch Collection r مخطوطات الكوديكس: نوع من لفافات التوراة النادرة للغاية، مرقوم وموضح عليه مخارج الحروف و ألحان الكلمات و التجويد؛ ولقد امتاز

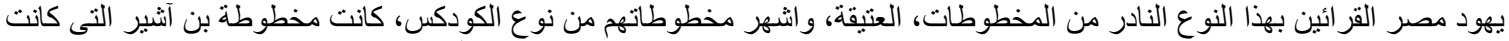

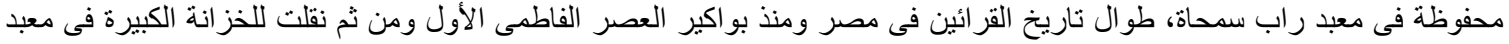

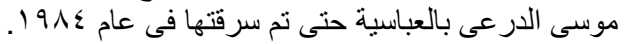




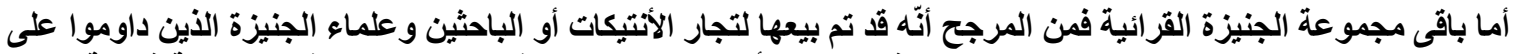

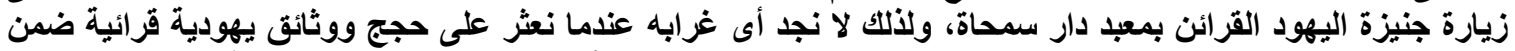

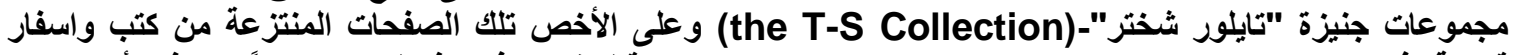

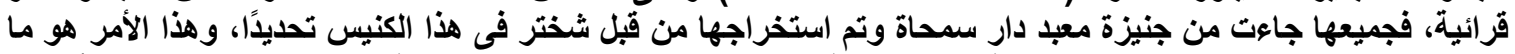

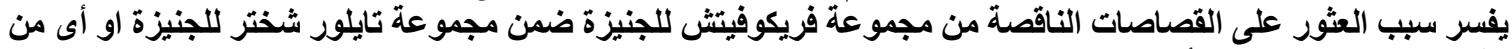
باقى مجموعات الجنيزة الأخرى المنتشرة حول العالم" (Vidro, 2013) (Ben-Shammai, 2010)

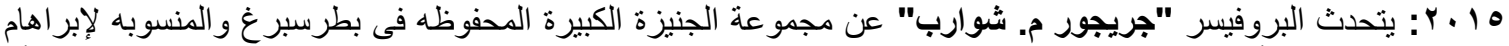

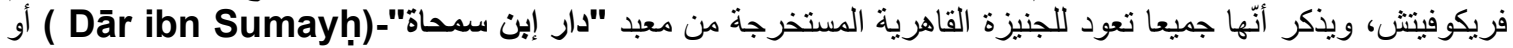

"راف سمحاة" (Rav Simḥa) بالقاهرة: (1)

17 ـ ب ب يشير "سابيان شميديتيك"-(Sabine Schmidtke) الذى درس فكر المعتزله وتأثر اليهود القر ائين به، إلى مجموعة

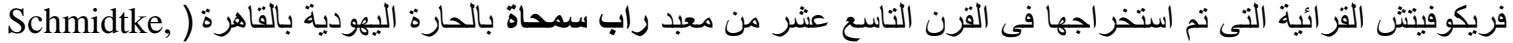

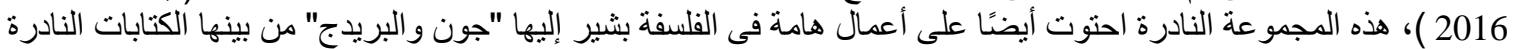

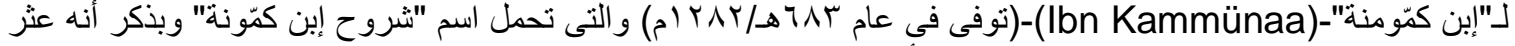

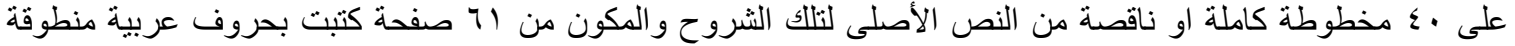
بالعبرية، ضمن مكتبة معبد "راب سمحاة"-(Rab Simha) بالقاهرة، إلى جانب ستة من مخطوطات "الثنهر ازورىى"-

.(Walbridge, 2016) (Sahrazüri)

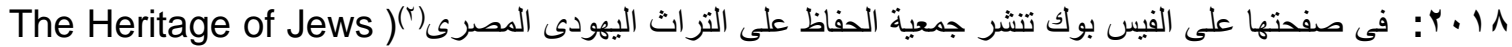
in Egypt)، مناقثة حول أطلال و بقايا "معبد راب سمحاة" بحارة اليهود، فتحت عنوان "الحرنفش" كتب محرر الصفحة:

"الحرنفش! تفتح البوابه التى توّجت بنجمة داود إلى شارع الحرنفش، بينما الجهة الأخرى فهى تقود إلى زقاق حيث يقف

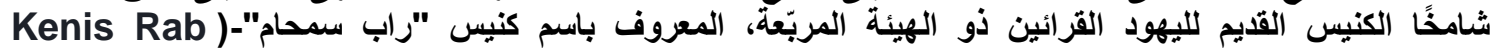

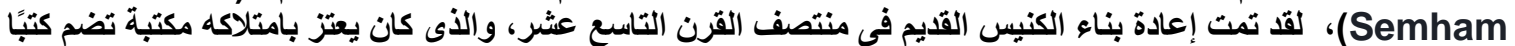

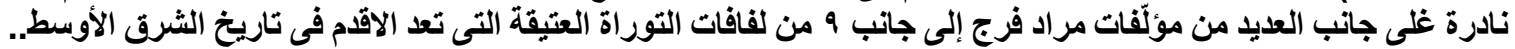

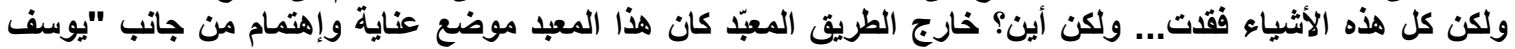

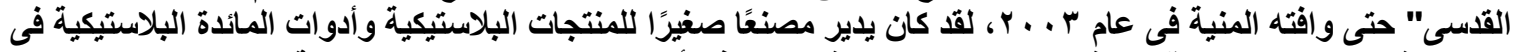

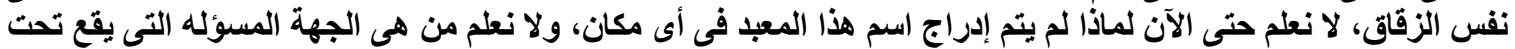

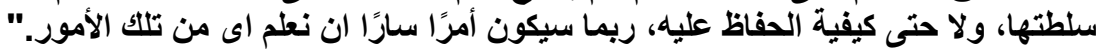

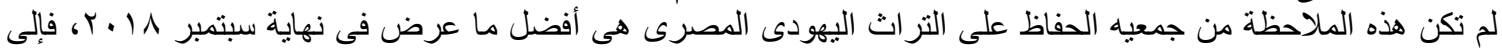

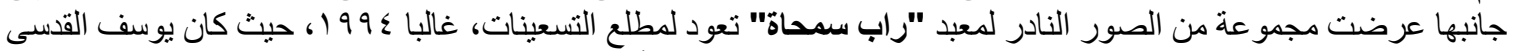

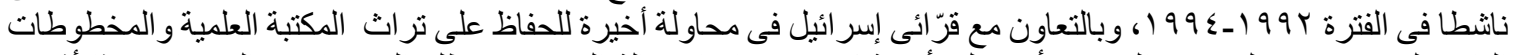

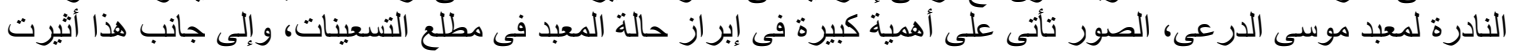

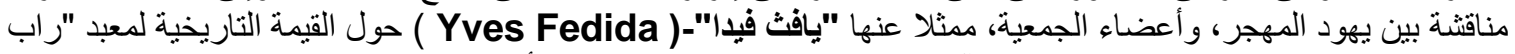

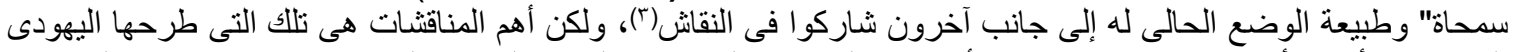
المخضرم "ألبرت أرييه"-(Albert Arie)، أحد كبار المعمرين الذكور من الطائفة اليهودية الباقية فى مصر ، و هو من الربانيين:

${ }^{1}$ Gregor M Schwarb: "Review of O. Tirosh-Becker, גנזי חז"ל בספרות הקראית בימי הביניים [Rabbinic Excerpts in Medieval Karaite Literature]. Volume 1: Philological and Linguistic Studies; Volume 2: A Critical Annotated Scientific Edition of the Texts, Jerusalem: The Bialik Institute, 2011.", Journal of Semitic Studies 60,2 (2015), pp. 511-514, 2015.

${ }^{2}$ The Heritage of Jews in Egypt: "Khoronfish! " , Facebook-Page, on 30 Septemper2018: " Khoronfish ! The gated entrance studded with Stars of David, opens onto Khoronfish street. The other side leads to an alleyway. There stands a square shaped, and therefore rare, old Karaïte synagogue known as Kenis Rab Semham. This ancient synagogue was rebuilt in the Mid-19th century. It boasted a library of rare books, many works of Mourad Farag, as well as 9 of the oldest Torah scrolls in the Middle East - all gone... but where? Outside the beaten track, it was watched over by Youssef El Kodsi until his death in 2003. He ran a small plastic cutlery factory and warehouse in the same alleyway. We do not know why this synagogue is listed nowhere nor under whose authority it falls nor how it is preserved. It would be interesting to find out..."

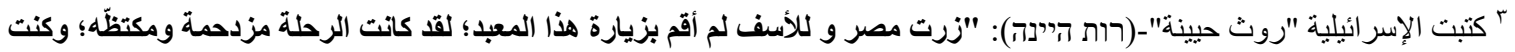

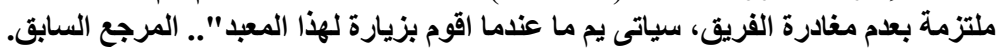


".. لقد تم الحفاظ على مكتبه معبد راب سمحاة، وهى اليوم موجودة فى كنيس اليهود القرائين بالعباسية،

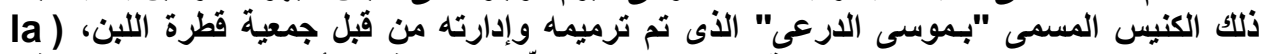

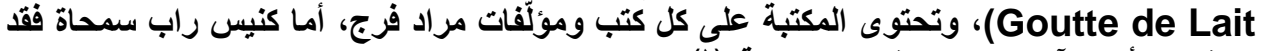
إختقى والأمر الآن موضع تحقيق ومحاكمة" (')

مجموعة الصوور التى تم عرضها لمعبد دار سمحاة بحارة اليهود من قبل جمعية الحفاظ على التراث اليهودى المصرى سنة

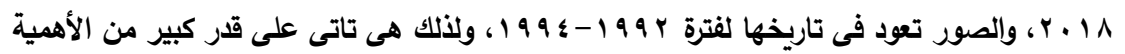
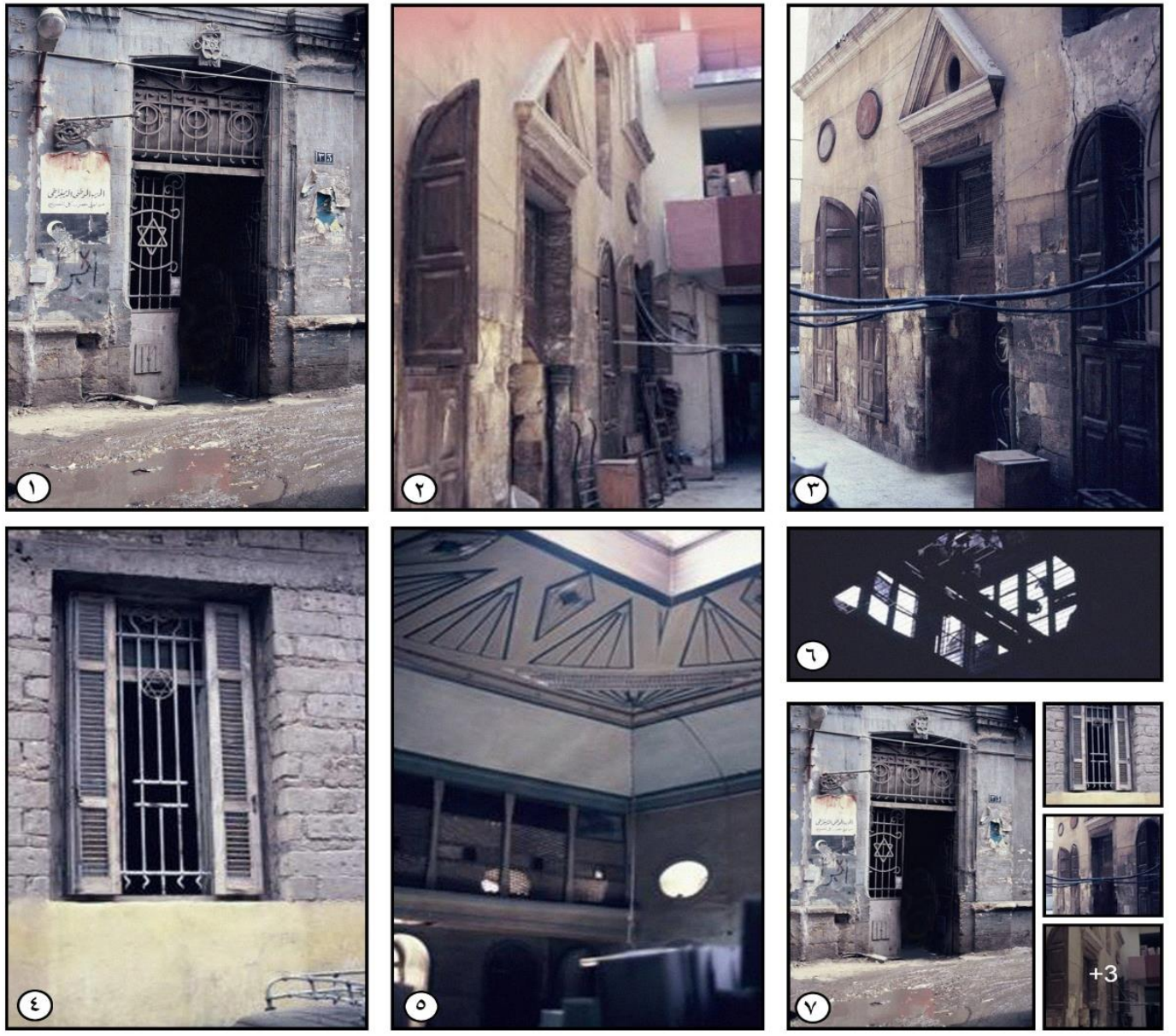

صورة مدخل المنزل يحمل شعار نجمة داوود والموجود بثارع درب الكنيس، بحارة اليهود

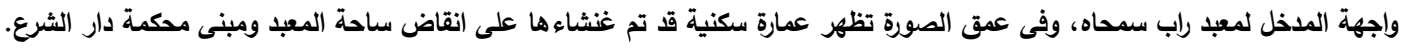
(r) (ץ) منظر آخر لواجهة مدخل المبد ولكن من الجهة الأخرى

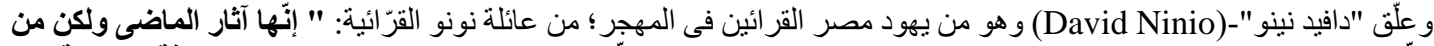

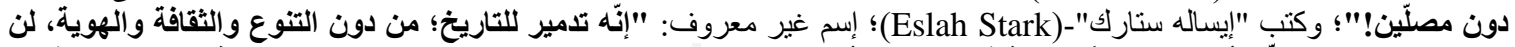

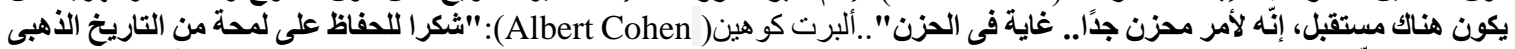

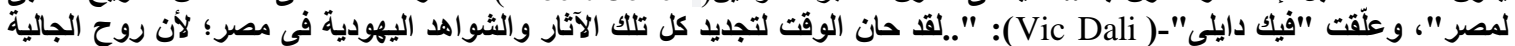

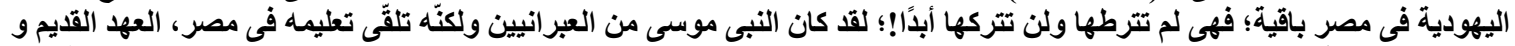

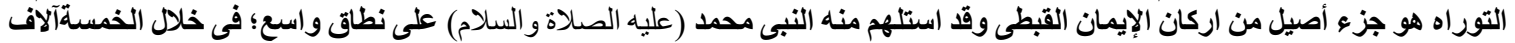

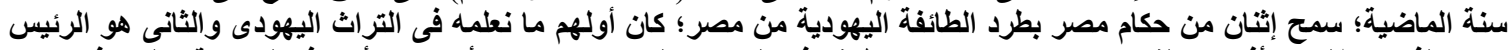

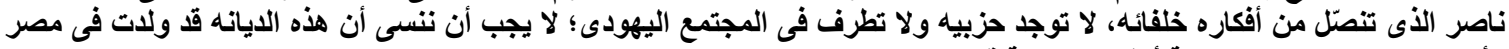

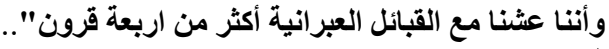
مرجع سابق. 


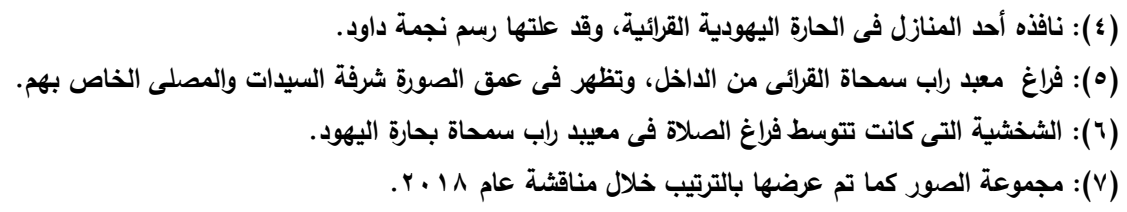

؛ ت نتائج الار اسة البحثية

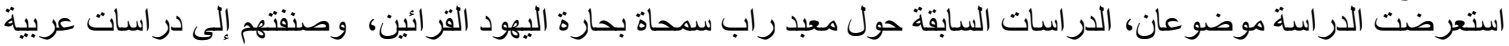

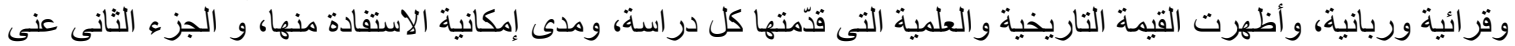

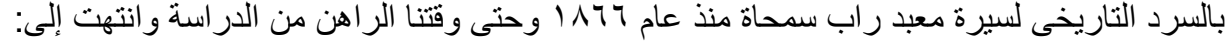

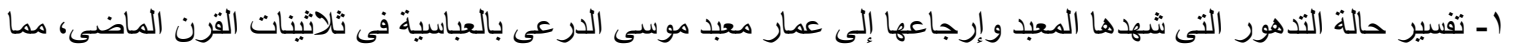

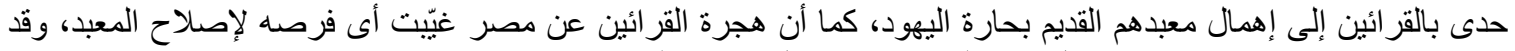

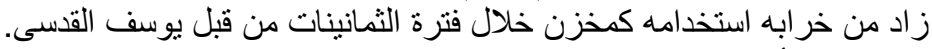

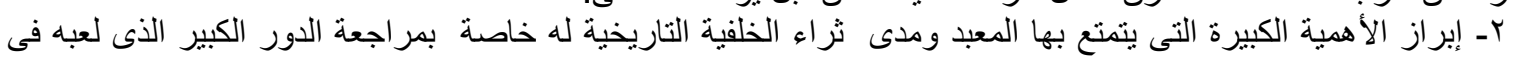

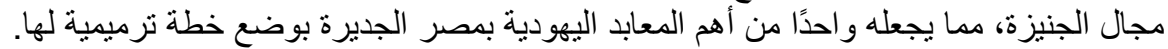

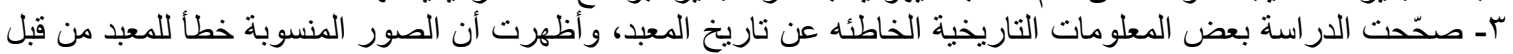
كل من جالك حسون و عرفه عبده نعود لمقبرة عائلة منشا القر ائية بالبساتين.

\section{م توصيات الاراسة البحثية}

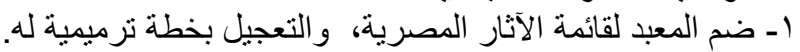

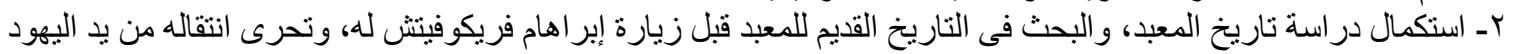

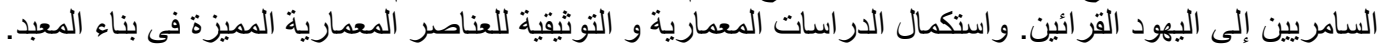

References

الاتحاد الإلسر ائيلى: العدد رقم (5) من السنة اللولى، القاهرة، 10 يونية من سنة ؟ 94 أ.

The Israeli Federation Weekly: Issue (5) of the first year, Cairo, 15 June 1924.

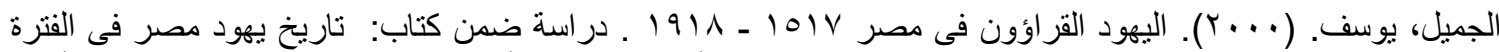

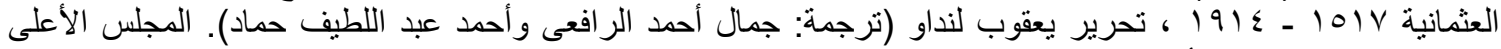
للافقافة، القاهرة (العمل الأصلي نشر في 1911 (1) ).

EI-Gamil, Y. (2000). Karaite Jews in Egypt, 1517-1918. In Landau, J. M. (Ed.), The Jews in Ottoman Egypt (1517-1914) (pp. 604-651) (Al-Rifai J. A. and Hammad A. A. trans.). Cairo, Egypt: Supreme Council of Culture (Original work published 1988).

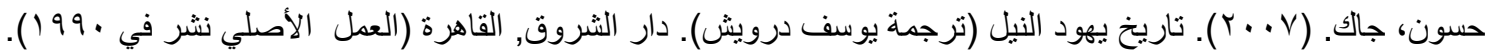
Hassoun, J. (2007). Histoire des Juifs du Nil (Y. Darwish, Trans.) Cairo, Egypt: Dar al Shorouk (Original work published 1990).

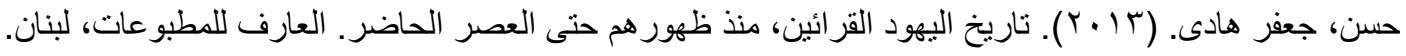

Hassan, J. H. (2013). History of the Karaite Jews. Lebanon: Alaref for Publications.

حسن، جعفر هادى. (919 (1): فرقة القر ائين اليهود، دراسة فى نشأة الفرقة وعقائدها وتاريخها إلى العصر الحاضر ـ مؤسسة الفجر، بيروت- لندن. - ان.

Hassan, J. H. (1989). The Jewish Qaraite Sect. Beirut - London: Al-Fajr Foundation.

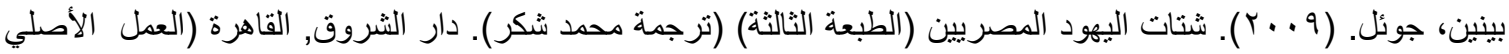
نشر في .99 (19). 
Beinin, J. (2009). The Dispersion of Egyptian Jewry: Culture, Politics, and the Formation of a Modern Diaspora (3rd ed.) (M. Shokr, Trans.) Cairo, Egypt: Dar al Shorouk (Original work published 1998)

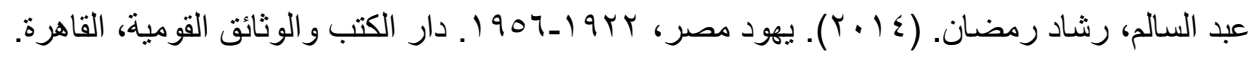

Abd al Salem, R. R. (2014).The Jews of Egypt, 1922-1956. Cairo, Egypt: The Egyptian National Library and Archives.

$$
\text { عطا، زبيدة محمد. (11) (1). يهود مصر : التاريخ الجنماعى و القتصادى. عين للار اسات و البحوث، الجيزة. }
$$

Ata, Z. M. (2011). The Jews of Egypt: The Social and Economic History. Giza, Egypt: Ein for human and social studies

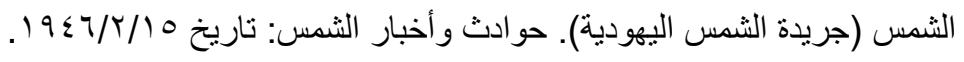

Alshams (Alshams Jewish newspaper): Incidents and news of Alshams: 15/2/1946.

$$
\text { على، عرفه عبده. ( (1 نوفمبر, } 9199 \text { (1). المحافل والمعابد اليهودية فى مصر . مجلة الهلال (1) (1). }
$$

Ali, A. A. (1989, November 1). Lodges and synagogues in Egypt. Al-helal Magazine('1)

$$
\text { على، عرفه عبده. (1991 (1). ملف اليهود فى مصر الحديثة. مكتبة مدبولى, القاهرة. }
$$

Ali, A. A. (1993). The Jews' file in modern Egypt. Cairo, Egypt: Madbouli Bookshop.

على، عرفه عبده. ( . . r). يهود مصر منذ عصر الفر اعنه حتى عام 2000م. تاريخ المصريينن الهيئة العامة للكتاب، القاهرة.

Ali, A. A. (2000). The Jews of Egypt since the time of the Pharaohs until the year 2000. Cairo, Egypt: General Egyptian Book Organization

$$
\text { على، عرفه عبده. (• ( • (Y). يهود مصر، منذ الخروج الأول إلى الخروج الثانى. وزارة الثقافة، القاهرة. }
$$

Ali, A. A. (2010). The Jews of Egypt, from the first Exodus to the second Exodus. Cairo, Egypt: Ministry of Culture

قاسم، قاسم عبده. (10 • ب). اليهود فى مصر من الفتح الإسلامى حتى الغزو العثمانى, قراءة فى تاريخ مصر الإجتماعى. عين اللار اسات، القاهرة.

Qasim, Q. A. (2015). The Jews in Egypt from the Islamic Conquest until the Ottoman Conquest, A Reading in Egypt's Social History. Giza, Egypt: Ein for human and social studies

الوقاد، محاسن محمد. (999 (19). اليهود فى مصر المملوكية، فى ضوء وثائق الجنيزة. تاريخ المصريين (عدد هب (1). الهيئة المصرية العامة للكتاب، القاهرة.

Al-Waqqad, M. M. (1999). Jews in Mamluk Egypt, in light of the Geniza documents. History of the Egyptians (Vol. 135). Cairo, Egypt: General Egyptian Book Organization

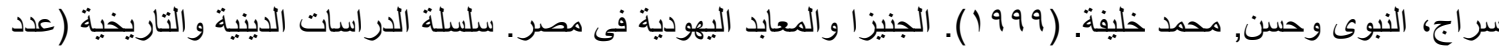
9). مركز الدراسات الثرقية بجامعة القاهرة، القاهرة.

Siraj, A. J. and Hasan, M. K. (1999). Genizah and Jewish temples in Egypt. Religious and Historical Studies Series (Vol.9). Cairo, Egypt: Cairo University's Center of Oriental Studies.

$$
\text { سر اج، النبوى. (991 (191). المعابد اليهودية ودور ها فى حياة اليهود بمصر . شركة الإسالم بمصر للطباعة، القاهرة. }
$$

Siraj, A. J. (1998). Synagogues and their role in the life of the Jews in Egypt. Cairo, Egypt: Islam Co. For Printing

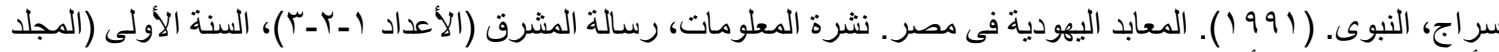

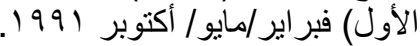

Siraj, A. J. (1991). Synagogues in Egypt. Information Bulletin, Risalat Almashriq, Vol. 1(1,2,3) February / May / October 1991.

ميطال، يور ام. (799 (1)..: الآثار اليهودية فى مصر (ترجمة الضوى يونس وعمرو زكريا ). دار الفكر الحديث، القس (العمل الأصلي نشر في 1990 (1997).

Meital, Y. (1996). Jewish sites in Egypt (Younis, A. and Zakaria, A., Trans.) Jerusalem: Dar alFiqr al-Hadith (Original work published 1995). 


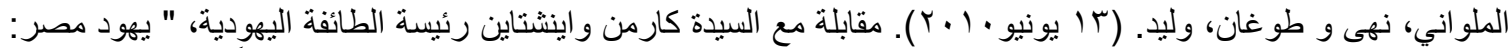

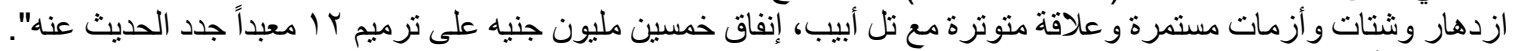
جريدة الرأى أى أن

Al-Mallawany, N. \& Tugan, W. (15 June 2010). The Jews of Egypt: Prosperity, Diaspora, Continuous Crises, Tense Relationship with Tel Aviv, Spending Fifty Million Pounds on Restoring 12 New Temples - An interview with Carmen Weinstein, Head of the Jewish Communit,. Cairo, Egypt: Al-Rai Newspaper

(KJA), T. K. (2016). Karaite Customs and Traditions. https://www.karaites.org.

(Rabbi), M. Y. (1995). " An Overview of Karaite Theology \& History". "The Karaite Encyclopedia," complied by Jewish historian Nathan Schur, using Karaite resources. Peter Lang Frankfurt/Berlin/New York.

Adler, E. N. (1905). Jews in Many Lands. Philaddelphia, The Jewish Puplication Society Of America.

Al-Qudsï, M. (2002). Just for the Records in the History of the Karaite Jews in Egypt in Modern Times.

Al-Qudsï, M. (2006). "The Karaite Jews of Egypt, 1882-1986".

Beinin, J. (2003). "The Karites in Modern Egypt" a chapter within abook , Edited by: Meira Polliack: Karaite Judaism: A Guide to Its History and Literary Sourcesm Brill.

Beinin, J. (2005). The Dispersion of Egyptian Jewry: Culture, Politics, and the Formation of a Modern Diaspora". AUC, 186.

Ben-Shammai, H. (2010). 'Is "the Cairo Genizah" a proper name or a generic noun? On the relationship between the genizot of the Ben Ezra and the Dār Simha synagogues'. B. Outhwaite \& S. Bhayro (eds), 'From a Sacred Source', Leiden/Boston, Brill .

Cassuto, D. (1988). "A Selection of Synagogues in Old Cairo". Bulletin of the Israeli Academic Center in Cairo, 4-13.

Committee, A. (1984). Juifs d'Égypte:Images et textes. 2nd ed.Paris: Editions du Scribe.

D.Sklare. (2003). "A Guide to Collections of karaite Manuscripts". M.Polliak (ed.);"Karaite Judaism: a guide to its history and Literary Sources", Leiden.

Daniel, N. (2004). Synagogue Caire. Lecture presented in Alexandria.

Daniel, N. (2006). " Synagogues de Le Egypte". (http://www.nebidaniel.org).

Elkin, Z. M.-S. (2000). 'Abraham Firkovitch and the Cairo Genizahs in the light of his personal archive' (Hebrew). Pe'amim 90,Press.

Fahi. (2014). The Karaite Families. after: Farhi Orgnization, ID: I1150 , F197 .

Khoronfish. (2018). The Heritage of Jews in Egypt. Facebook-Page.

Licha, S. (2003). November Book Review \& Give-Away: The Karaite Jews of Egypt? (abluethread.com) a karaite blog for American Jews.

Licha, S. (2013). What Kind of Jew Are You? (abluethread.com) a karaite blog for American Jews. Mosseri, J. (1914). "The Synagogues of Egypt: Past and Present" the Jewish. 31- 44.

Outhwaite, B., \& Bhayro, S. (2010). a Sacred Genizah Studies in Honour of Professor Stefan C. Reif. BRILL,Press. 
Reif, S. (2000). A Jewish Archive from Old Cairo: the History of Cambridge University's Genizah Collection. Richmond, Surrey,Press.

Schmidtke, S. (2016). " The Oxford Handbook of Islamic Theology". Oxford University .

Schwarb, G. M. (2015). " Review of O. Tirosh-Becker, גנזי חז"ל בספרות הקראית בימי הביניים [Rabbinic Excerpts in Medieval Karaite Literature]. Volume 1: Philological and Linguistic Studies, Volume 2: A Critical Annotated Scientific Edition of the Texts. The Bialik Institute , Journal of semitic studies 60, 2, Jerusalem.

Shapira, D. (2003). Avraham Firkowicz in Istanbul. Karam Yayinlari .

Vidro, N. (2013). A medieval Karaite pedagogical grammar of Hebrew". Taylor-Schechter Genizah Research Unit, University of Cambridge,.

Walbridge, J. (2016). "Suhrawardi's intimations of the Tablet and the Throne", Ed: Khaled ElRouayheb ‘Sabine Schmidtke: "The Oxford Handbook of Islamic Philosophy. "The Oxford Handbook of Islamic Philosophy",Oxford University , 259.

Jehoash Hirshberg (1988). "Musikah ke-gorem le-likud ha-kehilah ha-kara'it be-san frantzisko," Pe‘amim 32 (1988):73.

\title{
Rab Simḥāh Synagogue in the Karaites's Jewish quarter at Cairo; Historical study
}

\author{
Ahmed Zakaria Zaki Ali \\ Department of Planning and Urban Design, Faculty of Engineering, Ain Shams University
}

\begin{abstract}
Rab Simhāh Synagogue is a small square building located in the Kariate allay in the Jewish quarter in Cairo at the district El-Gammalia, it has been standing there for more than500 years serving as the main synagogue for Egyptian Karaites, and as a house of their religious court, in this long period, the synagogue had been restored and rebuilt for some times, but it's still one of the most important monuments attributed to one of the most strange Jewish sects. The simple and direct architecture isn't a good reflection of the historical richness and how this Synagogue is bonded to secrets of the Egyptian Jewish society, the historical treasure of that building is the Kariate's Geniza, which had been discovered late 19th, that why the name of the Synagogue kept repeating from then tell now, in Arab and Jewish studies by a wide range of scholars interested in documenting and studying Egyptian Geniza, but yet there is no single study had been devoted to the architecture or historical value of this monument, this shortage of research have been reflected on the neglected and ignores the building suffers today because it never been indexed on any Egyptian monuments list, it is candid to be brought down to the ground while all of the Synagogue's history lost with the destruction's dust.

By reviewing all previous resources; Arabic, Karaites, and Rabbinic involved with the history of Rab Simhāh Synagogue, to build historical documentation of this architectural monument in modern time starting from year1866 to now, this documentation may give this building a chance to remain, by revealing out its true history.
\end{abstract}

Key words: Jews of Egypt; Karaites; Rab simha; synagogue architecture; Cairo; Jewish quarter 